\title{
It's a gas: Oxidative dehydrogenation of propane over boron nitride catalysts
}

\author{
Peter Kraus ${ }^{a *}$ R. Peter Lindstedt ${ }^{b}$ \\ a) School of Molecular and Life Sciences, \\ Curtin University, \\ GPO Box U1987, Perth 6845, WA \\ b) Department of Mechanical Engineering, \\ Imperial College London, \\ Exhibition Road, London SW7 2AZ
}

\section{Abstract}

Boron nitride and related boron-containing materials have recently been suggested as very promising catalysts in the oxidative dehydrogenation of propane. The high selectivity towards propylene at comparably high conversion significantly exceeds the performance of established vanadium-based catalysts. In the current work we show that the high selectivity towards propylene and ethylene is fully consistent with a gas-phase conversion mechanism and that it can be modelled reasonably well by the recent detailed microkinetic reaction mechanism of Hashemi and coworkers. Our analysis, using six heterogeneous catalytic reaction pathways, each representing a hypothetical limit case, shows that the boron nitride catalyst is responsible for initiating the gas-phase chemistry. We also show that the experimental $\mathrm{C}_{2}: \mathrm{C}_{1}$ product ratios with an undiluted catalytic bed can be reproduced by incorporating $\mathrm{C}-\mathrm{C}$ bond scission into the catalytic surface chemistry. The trends in the selectivities of minor species upon dilution of the catalytic bed and upon varying the $\mathrm{C}_{3} \mathrm{H}_{8} / \mathrm{O}_{2}$ inlet ratio, as observed by Venegas and Hermans, are here explained as gas-phase phenomena. Hence, the oxidative dehydrogenation of propane over boron nitride catalysts is an example of a coupled gas- and catalytic- chemistry system. The current work also highlights the importance of modelling of the complete heated zone, including the rear heat shields and reactor padding if present.

\section{Introduction}

2 "It is surprising that boron nitride $(\mathrm{BN})$, a material known for its high stability under oxidative condi3 tions, is catalytically active at all." I Since this landmark 2016 publication by Grant et al. 11 in Science, 4 boron-containing materials have become a hot topic in oxidative dehydrogenation (ODH), and with

${ }^{*}$ E-mail: peter.kraus@curtin.edu.au 
5

6 7 The performance of some BN materials remains stable up to 300 hours on stream ${ }^{2]}$ and catalysts can 8 be regenerated by co-feeding $\mathrm{NH}_{3} .{ }^{4}$ In fact, it seems good ODH performance can be obtained with any 9 material provided it contains boron. $\frac{516}{5}$

good reason. The claimed selectivity to propylene $\left(S\left(\mathrm{C}_{3} \mathrm{H}_{6}\right)\right)$ is $80 \%$ at propane conversion $\left(X\left(\mathrm{C}_{3} \mathrm{H}_{8}\right)\right)$ of $21 \%$, ${ }^{2}$ while established vanadium-based catalysts offer only $60 \%$ selectivity at half the conversion. 113$]$ Most studies of ODH of alkanes over BN focus on the catalytic surface chemistry, and despite the high temperatures required, usually in excess of $500^{\circ} \mathrm{C}$, the potential contribution of gas-phase chemistry remains comparably unassessed. This is understandable as blank experiments with $\mathrm{SiO}_{2}$ instead of $\mathrm{BN}$ in the reactor show almost no conversion. ${ }^{417}$ However, the operating conditions across the various catalytic tests have not been standardised, ${ }^{8}$ making comparisons between datasets difficult. Pretreatment, heat transport, diluent and dilution, reactor dimensions, and feed composition all play a significant role in the activity of hexagonal boron nitride $(\mathrm{hBN}) .[689]$ Venegas et al. proposed that the observed catalytic activity of diluted $\mathrm{hBN}$ for $\mathrm{ODH}$ of propane may be rooted in gas-phase oxidation chemistry, initiated by catalytic surface reactions, and that hBN may even act as a radical quenching agent. ${ }^{8}$ This was later reinforced by the suggestion that the role of the gas-phase must be established and incorporated in future model development ${ }^{6}$. Such mechanisms have been proposed for ODH of butane $\frac{10}{10}$ and more recently propane. ${ }^{9}$

It is a fortunate coincidence that a "low-temperature" (from a combustion point of view) gas phase mechanism for propane oxidation has been recently published. 11 This allows us to investigate the relative gas-phase and catalytic contributions to the observed ODH of propane. We accordingly explore the differences between the predicted gas-phase behaviour and observed catalytic performance under dry conditions ${ }^{[}$by coupling six catalytic "limit" mechanisms, derived from literature, to the gasphase chemistry of Hashemi et al. 11] These mechanisms include direct dissociative adsorption as well as oxygen-mediated Eley-Rideal adsorption pathways, and investigate the potential impact of catalyticallygenerated propylene, propoxy radicals, propyl radicals, or C-C scission products on the gas-phase chemistry. The mechanisms are evaluated against the reference experimental conditions that span a range of residence times and consider the impact of dilution of the catalyst in dry feed ${ }^{[}$with the impact of steam and $\mathrm{O}_{2}$ concentration in the feed thoroughly evaluated by Venegas et al. 9 


\section{Computational methods}

The gas-phase and heterogeneous modelling in this work was performed using Cantera version 2.4. 12 All fitting is performed with the nonlinear least squares routine curve_fit from the scipy.optimize Python library. The inputs used in the modelling, the resulting data, and the post-processing routines are all included in the Binder-compatible Supporting Information archive.

\subsection{Gas-phase chemistry}

The following gas-phase models are used in this work: i) the "DTU" model developed for high-pressure oxidation of propane, 11] ii) the mechanism of Burluka et al. developed to model laminar burning velocities of $\mathrm{C}_{3}$ oxygenated species, 13 and iii) the "JetSurF" mechanism developed for high-temperature combustion of jet fuel surrogate mixtures. 14 The DTU model includes low-temperature chemistry of the hydroperoxyalkyl $(\mathrm{QOOH})$ radicals, 15 as well as revised $\mathrm{C}_{3} \mathrm{H}_{8}$ thermal activation 16 and radical abstraction 1117 rates. The Burluka model predates this low-temperature QOOH chemistry, but it includes more complete decomposition pathways of propylene oxide $\left(\mathrm{c}-\mathrm{C}_{3} \mathrm{H}_{6} \mathrm{O}\right)$ which we show to be a potentially significant minor product. Finally, JetSurF is based on a $\mathrm{C}_{1}-\mathrm{C}_{4}$ submechanism $\underline{18}$ that was extensively validated for higher temperatures and is mainly included for comparison purposes.

The ignition delay and selectivity-vs-conversion plots shown in Section 3 are modelled using an adiabatic constant pressure reactor, with the size of the time step adjusted dynamically by the solver. The ignition point $\tau$ is determined as the time corresponding to the maximum in the time derivative of the $\mathrm{OH}$ concentration $(\tau=\arg \max f(t):=d[\mathrm{OH}] / d t)$. At the current temperatures, propane autoignition proceeds in two stages, with the first stage due to a combination of $\mathrm{HO}_{2}$ and $\mathrm{OH}$ radical chemistry, and the second, high-temperature ignition stage characterised by $\mathrm{OH}$ chemistry. $\frac{19}{19} \tau$ determined using the above method corresponds to the latter, high-temperature ignition delay, and therefore corresponds to an upper boundary.

\subsection{Catalytic surface chemistry}

A H/O sub-mechanism (14 reactions and thermochemistry) obtained from a $\mathrm{CH}_{4}$ oxidation model developed for platinum, ${ }^{20}$ see Table 1 , is used as the basis for the heterogeneous models. The choice 
Table 1: The catalytic H/O sub-mechanism [20] in the form $A T^{\beta} e^{-E_{A} / R T}$, where $\theta(X)$ is surface fraction of species $X, s_{0}$ is the sticking coefficient, $s$ indicates a surface bond and $\dagger$ a first order rate law.

\begin{tabular}{l|c|c|r|r}
\hline$\#$ & Reaction & $A(\mathrm{~m}, \mathrm{~mol}, \mathrm{~s})$ & $\beta(-)$ & $E_{A}(\mathrm{~kJ} / \mathrm{mol})$ \\
\hline $\mathrm{R} 1$ & $\mathrm{H}_{2}+2^{\dagger} \mathrm{B} s \rightarrow 2 \mathrm{H} s$ & $4.46 \times 10^{4}$ & 0.5 & 0 \\
$\mathrm{R} 2$ & $2 \mathrm{H} s \rightarrow \mathrm{H}_{2}+2 \mathrm{~B} s$ & $3.7 \times 10^{15}$ & 0 & $67.4-6 \times \theta(\mathrm{H} s)$ \\
$\mathrm{R} 3$ & $\mathrm{H}+\mathrm{B} s \rightarrow \mathrm{H} s$ & $s_{0}=1$ & 0 & 0 \\
$\mathrm{R} 4$ & $\mathrm{O}_{2}+2 \mathrm{~B} s \rightarrow 2 \mathrm{O} s$ & $1.8 \times 10^{9}$ & -0.5 & 0 \\
$\mathrm{R} 5$ & $\mathrm{O}_{2}+2 \mathrm{~B} s \rightarrow 2 \mathrm{O} s$ & $s_{0}=0.023$ & 0 & 0 \\
$\mathrm{R} 6$ & $2 \mathrm{O} s \rightarrow \mathrm{O}_{2}+2 \mathrm{~B} s$ & $3.7 \times 10^{15}$ & 0 & $213.2-60 \times \theta(\mathrm{O} s)$ \\
$\mathrm{R} 7$ & $\mathrm{O}+\mathrm{B} s \rightarrow \mathrm{O} s$ & $s_{0}=1$ & 0 & 0 \\
$\mathrm{R} 8$ & $\mathrm{H}_{2} \mathrm{O}+\mathrm{B} s \rightarrow \mathrm{H}_{2} \mathrm{O} s$ & $s_{0}=0.75$ & 0 & 0 \\
$\mathrm{R} 9$ & $\mathrm{H}_{2} \mathrm{O} s \rightarrow \mathrm{H}_{2} \mathrm{O}+\mathrm{B} s$ & $1 \times 10^{13}$ & 0 & 40.3 \\
$\mathrm{R} 10$ & $\mathrm{OH}+\mathrm{B} s \rightarrow \mathrm{OH} s$ & $s_{0}=1$ & 0 & 0 \\
$\mathrm{R} 11$ & $\mathrm{OH} s \rightarrow \mathrm{OH}+\mathrm{B} s$ & $1 \times 10^{13}$ & 0 & 192.8 \\
$\mathrm{R} 12$ & $\mathrm{H} s+\mathrm{O} s \leftrightarrow \mathrm{OH} s+\mathrm{B} s$ & $3.7 \times 10^{15}$ & 0 & 11.5 \\
$\mathrm{R} 13$ & $\mathrm{H} s+\mathrm{OH} s \leftrightarrow \mathrm{H}_{2} \mathrm{O} s+\mathrm{B} s$ & $3.7 \times 10^{15}$ & 0 & 17.4 \\
$\mathrm{R} 14$ & $\mathrm{OH} s+\mathrm{OH} s \leftrightarrow \mathrm{H}_{2} \mathrm{O} s+\mathrm{O} s$ & $3.7 \times 10^{15}$ & 0 & 48.2 \\
\hline
\end{tabular}

is one of convenience as the mechanism is distributed with Cantera. Most pre-exponential factors are order-of-magnitude estimates $\left(10^{13} \mathrm{~s}^{-1}\right.$ for desorptions and $3.7 \times 10^{15} \mathrm{~m}^{3} \mathrm{~mol}^{-1} \mathrm{~s}^{-1}$ for bimolecular surface reactions). The mechanism is computationally efficient due to its small size. All original parameters are retained with the site density adjusted to reproduce the conversion observed with the current hBN based catalyst. The sensitivities to the site density $(\Gamma)$ and oxygen adsorption parameters are accordingly assessed below. The thermochemistry of additional surface species is estimated from the corresponding gas-phase species in the DTU mechanism without further correction. In our previous work on Pt and $\mathrm{Rh}$, the thermochemistry of the surface species was corrected by the heat of adsorption of the gas-phase species, obtained from systematic semi-empirical estimates. 21 Similar corrections for hBN would require values for the atomic heats of adsorption, which are currently unavailable and would have to be estimated. As a result, we introduced irreversible catalytic reaction steps (i.e. separate forward and reverse reactions) for the $\mathrm{C}_{3} / \mathrm{C}_{2} / \mathrm{C}_{1}$ surface chemistry.

Table 2: Properties of materials used in the heterogeneous model, where $\kappa$ is the thermal conductivity, $\rho$ the density and $S_{A}$ the surface area.

\begin{tabular}{l|r|r|r}
\hline & $\kappa\left(\mathrm{W} \mathrm{m}^{-1} \mathrm{~K}^{-1}\right)$ & $\rho\left(\mathrm{kg} \mathrm{m}^{-3}\right)$ & $S_{A}\left(\mathrm{~m}^{2} \mathrm{~kg}^{-1}\right)$ \\
\hline $\mathrm{SiO}_{2}$ & $3^{22}$ & 100 & 1000 \\
$\mathrm{hBN}$ & $33^{[8}$ & $410^{8}$ & $7000^{8}$ \\
$\mathrm{SiC}$ & $300^{23}$ & $860^{24}$ & $13000^{24}$ \\
\hline
\end{tabular}

The catalytic reactor is modelled using a plug flow approximation, with the modelled domain com- 


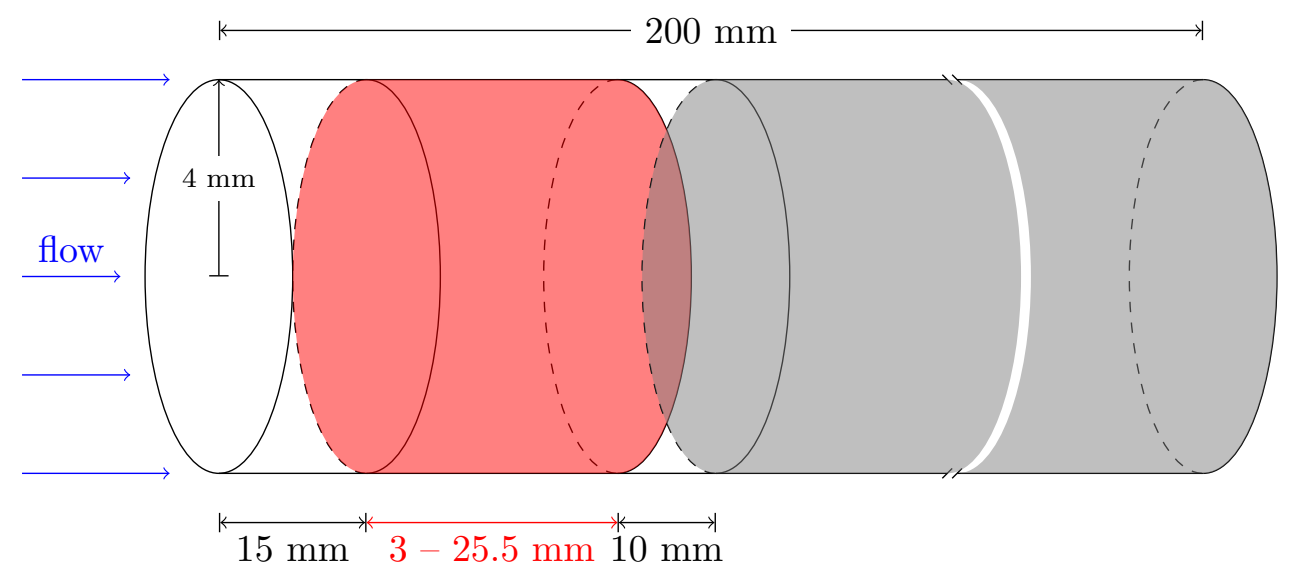

Figure 1: Schematic of the modelled reactor (not to scale). The catalytic section shown in red, front and rear heat shield sections filled with $\mathrm{SiO}_{2}$-wool in white, and reactor padding $\mathrm{SiO}_{2}$ chips in gray.

prising four sections shown in Fig. 1: a $\mathrm{SiO}_{2}$-wool heat shield, a catalytic section filled with $\mathrm{hBN}$ or optionally diluted with $\mathrm{SiC}$, another $\mathrm{SiO}_{2}$-wool heat shield, and the remainder of the reactor filled with $\mathrm{SiO}_{2}$ chips. The applied boundary conditions are taken from Venegas and Hermans where available: $[$ ] an inlet temperature of $298 \mathrm{~K}$; bath temperature of $773 \mathrm{~K}$; reactor radius $r$ of $4 \mathrm{~mm}$; the tortuosity of the catalytic and $\mathrm{SiO}_{2}$-wool sections set to 4; a porosity of the catalytic and $\mathrm{SiO}_{2}$-wool sections of 0.4; inlet flow rates between 40 and $160 \mathrm{ml} \mathrm{min}^{-1}$; length of the front and rear $\mathrm{SiO}_{2}$-wool sections of 15 and $10 \mathrm{~mm}$, respectively; length of the catalytic section between 3 and $25.5 \mathrm{~mm}$ depending on dilution of hBN with $\mathrm{SiC}$; an overall reactor length of $200 \mathrm{~mm}$. The inlet composition is $30 \% \mathrm{C}_{3} \mathrm{H}_{8}, 15 \% \mathrm{O}_{2}$, and $55 \% \mathrm{~N}_{2}$ by volume in all cases. The porosity and tortuosity of the section containing $\mathrm{SiO}_{2}$ chips is not provided; for simplicity we assume a tortuosity of 1 with the impact of porosity on conversion assessed below. The temperature of the modelled reactor is regulated by an isothermal bath coupled to the domain using a $d=4 \mathrm{~mm}$ thick wall with material dependent properties listed in Table 2 . The thermal conductances $U_{i}$ for each reactor section $i$ filled with material $\mathrm{X}$ are calculated according to Eq. (1), where $V_{i}$ is the volume of the $i$ th section.

$$
\begin{array}{r}
U_{i}=\kappa_{i}(\mathrm{X}) \times d /\left(V_{i} S_{A_{i}}(\mathrm{X}) \rho_{i}(\mathrm{X})\right) \\
A_{c_{i}}=V_{i} S_{A_{i}}(\mathrm{hBN}) \rho_{i}(\mathrm{hBN}) / f_{\text {dil }}
\end{array}
$$


The gas-phase chemistry is evaluated in all parts of the reactor with the heterogeneous mechanism enabled only in the catalytic section. In cases where $\mathrm{hBN}$ is diluted by $\mathrm{SiC}$, the catalytic area of each cell $A_{c_{i}}$ is scaled by the dilution factor $f_{\text {dil }}=V_{\text {bed }} / V_{\text {cat }} \in\{1.0,1.5,2.0,3.5,6.0,8.5\}$ (see Eq. (2)), and the thermal conductance is approximated as the weighted sum of the conductivities of $\mathrm{hBN}$ and $\mathrm{SiC}$. The density of grid points $i$ in the four sections of the modelled reactor is $10 / \mathrm{mm}$ for the front and rear $\mathrm{SiO}_{2}$-wool sections, $50 / \mathrm{mm}$ for the $\mathrm{hBN}$-containing section, and $1 / \mathrm{mm}$ for the section filled with $\mathrm{SiO}_{2}$ chips. Grid resolution independence was confirmed using a $10 \times$ finer grid with the conversion converged to within $6 \%$ and selectivities to within $1 \%$ for the two grids. The carbon-based selectivities $S$ and propane conversions $X$ reported in this work are product based, using Eqs. (3) and (4), respectively.

$$
\begin{aligned}
S(\operatorname{prod}) & =\frac{n_{\mathrm{C}}(\operatorname{prod}) x(i, \operatorname{prod}) f_{e}(i)}{\sum_{\mathrm{p} \neq \mathrm{C}_{3} \mathrm{H}_{8}} n_{\mathrm{C}}(\mathrm{p}) x(i, \mathrm{p}) f_{e}(i)} \\
X\left(\mathrm{C}_{3} \mathrm{H}_{8}\right) & =\frac{\sum_{\mathrm{p} \neq \mathrm{C}_{3} \mathrm{H}_{8}} n_{\mathrm{C}}(\mathrm{p}) x(i, \mathrm{p}) f_{e}(i)}{\sum_{\mathrm{r}} n_{\mathrm{C}}(\mathrm{r}) x(i, \mathrm{r}) f_{e}(i)}
\end{aligned}
$$

Here, $n_{\mathrm{C}}(\mathrm{p})$ is number of carbon atoms in species $\mathrm{p}, x(i, \mathrm{p})$ is the mole fraction of $\mathrm{p}$ in cell $i$, and $f_{e}(i)$ is the expansion factor defined as $f_{e}(i)=x\left(i, \mathrm{~N}_{2}\right) / x\left(0, \mathrm{~N}_{2}\right)$. Note that the index $\mathrm{p}$ runs over the products only, while the index $r$ runs over all species.

\section{Results and discussion}

To provide background for the aspects of the catalytic chemistry in the studied system, we first investigate the behaviour of the gas-phase chemistry as predicted by the DTU, 11 Burluka, 13 and JetSurF 14 reaction mechanisms under the experimental conditions. Then, we assess the impact of the surface chemistry of $\mathrm{hBN}$ on the selectivity of the overall system by using six hypothetical limiting heterogeneous reaction mechanisms. These limit mechanisms are used to probe the extremes of catalytic behaviour in the context of the gas-phase chemistry, by imposing $100 \%$ catalytic selectivity towards either propylene, propoxy radicals, propyl radicals, or $\mathrm{C}-\mathrm{C}$ scission products. We then explore the contribution of the gas-phase chemistry within these limits of possible catalytic behaviours and the experimentally observed conversion and selectivities. ${ }^{8}$ Finally, we briefly discuss more recent experiments where the 
inlet composition was varied. 9

\subsection{Gas-phase selectivities to major products}

The temperatures used in most investigations of propane $\mathrm{ODH}$ over $\mathrm{hBN}$ are usually in excess of $500^{\circ} \mathrm{C}$, which is higher than the usual conditions applied with vanadium-based catalysts. ${ }^{3}$ Such temperatures are potentially compatible with gas-phase ignition. Despite this, the contribution of gas-phase chemistry to the performance of $\mathrm{hBN}$ has not been quantified. Control experiments performed using a reactor filled only with quartz chips have been reported and show "negligible" conversion at well below 1\%. ${ }^{8}$ While conceptual catalytic and combined homo- and heterogeneous mechanisms have been proposed, $117[10$ only two studies have assessed the gas-phase behaviour: i) Loiland et al. applied a gas-phase microkinetic model (AramcoMech2.0) to study gas-phase effects, however, the imposed boundary conditions (a $100 \mathrm{~mm}$ long modelled section) appear incongrous with the geometry of the experimental reactor (38 $\mathrm{mm}$ long diluted catalytic bed in a $610 \mathrm{~mm}$ long heated quartz reactor). 25 ii) Venegas et al. performed a chemical kinetic analysis using a combined gas-phase and heterogeneous reaction mechanism, however, only selected gas-phase pathways were coupled to the surface chemistry instead of a comprehensive combustion mechanism. 9

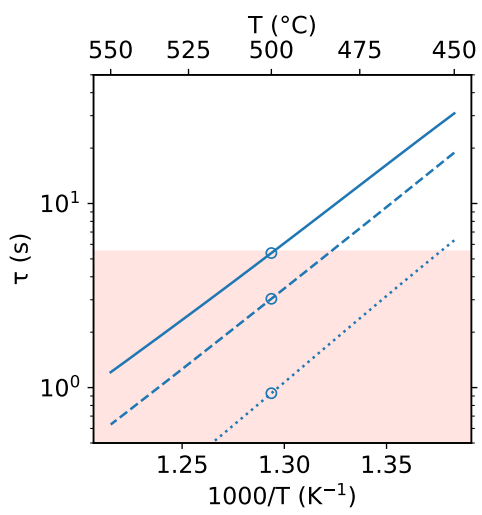

Figure 2: High temperature adiabatic ignition delay times $(\tau)$ based on the $\mathrm{OH}$ radical profile for a $15 \% \mathrm{O}_{2}, 30 \% \mathrm{C}_{3} \mathrm{H}_{8}, 55 \% \mathrm{~N}_{2}$ mixture as a function of the initial temperature at atmospheric pressure. The DTU mechanism ( - ) is compared to the Burluka (….) and JetSurF (--- ) mechanisms. The red area indicates $\tau$ for the reactor in the experiments of Venegas and Hermans. ${ }^{8}$ Circles highlight a temperature of $500^{\circ} \mathrm{C}$.

The high temperature ignition delays shown in Fig. 2 present an indication that gas-phase phenomena may play a non-negligible role under the studied conditions. At $500^{\circ} \mathrm{C}$, the DTU mechanism $(-)$ shows 
an ignition delay just outside the residence time domain in the experiments of Venegas and Hermans ${ }^{8}$ (red zone); the other two mechanisms (Burluka (…..) and JetSurF (-- )) predict ignition well within the experimental time domain. It should further be noted that the $\mathrm{HO}_{2}$ radical chemistry will be active in the gas phase at lower temperatures. The experimental temperature of $500^{\circ} \mathrm{C}$ is determined from a single thermocouple embedded in the catalytic bed, $\stackrel{8}{8}$ and despite best practices ensuring the bed is as isothermal as practicable, small inhomogeneities from the reaction temperature would have an exponential effect on the kinetics this close to self-ignition. We note that the ignition delay times shown in Fig. 2 are obtained from adiabatic calculations, while the catalytic reactor is likely close to the isothermal limit. The temperature rise for the adiabatic computations is $3 \mathrm{~K}$ at $1 \%$ conversion and reaches an upper limit of $103 \mathrm{~K}$ at $20 \%$ conversion. The gas phase contribution is expected to be correspondingly higher than observed experimentally. Therefore, further results from gas-phase calculations are presented as a function of conversion. For combined heterogeneous and gas-phase calculations, we model the reactor using a plug-flow approximation coupled to a heat bath, validated in Section 3.3 below.
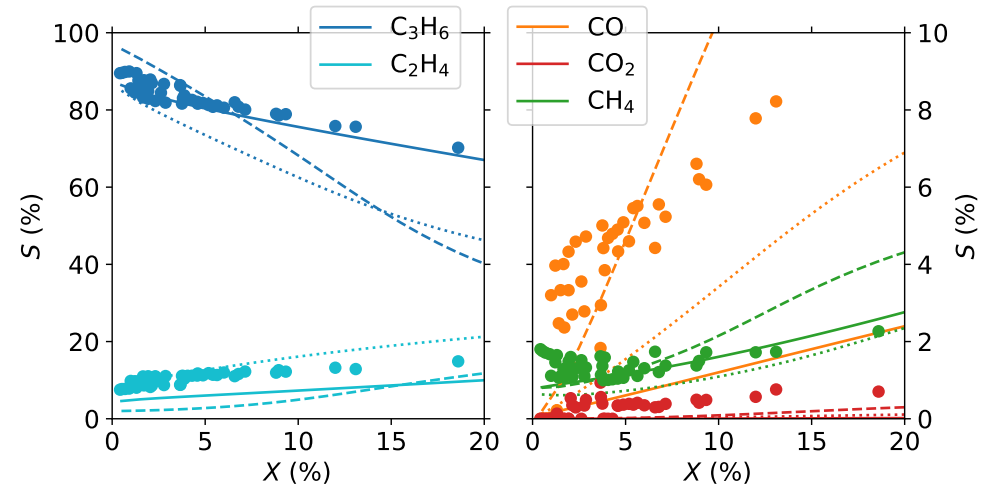

Figure 3: Selectivities $(S)$ vs conversion $(X)$ obtained exclusively from gas-phase kinetics. The DTU mechanism ( - ) is compared to the Burluka (......) and JetSurF (-- ) mechanisms and experimental data at all dilutions $(\bullet)$. ${ }^{8}$ The computations assume an adiabatic reactor with initial conditions of $500^{\circ} \mathrm{C}$ and atmospheric pressure, and a $15 \% \mathrm{O}_{2} / 30 \% \mathrm{C}_{3} \mathrm{H}_{8} / 55 \% \mathrm{~N}_{2}$ inlet composition.

The performance of $\mathrm{hBN}$ (and other B-containing materials) for ODH of propane is remarkable mainly due to the high selectivity to propylene and ethylene. However, as shown in Figure 3 , the high selectivity to both propylene $\left(\mathrm{C}_{3} \mathrm{H}_{6}\right.$, - $)$ and ethylene $\left(\mathrm{C}_{2} \mathrm{H}_{4},-\right)$ is consistent with the kinetics of the DTU gas-phase mechanism. The experimental $S\left(\mathrm{C}_{3} \mathrm{H}_{6}\right)$ at $X\left(\mathrm{C}_{3} \mathrm{H}_{8}\right) \leq 20 \%$ is matched almost exactly, while the trend in $S\left(\mathrm{C}_{2} \mathrm{H}_{4}\right)$ is predicted qualitatively with a constant underpredicion of $\approx 5 \%$ in the same conversion range. The other two mechanisms significantly underpredict the observed $\mathrm{S}\left(\mathrm{C}_{3} \mathrm{H}_{6}\right)$. For 
minor products, methane $\left(\mathrm{CH}_{4}, \bullet\right)$ is well predicted by the DTU $(-)$ and Burluka $(\cdots \cdots)$ mechanisms, but the main combustion product CO (-- ) is much better captured by JetSurF. The results indicate strongly that the pyrolysis part of the DTU mechanism is accurate while experimental selectivity to CO indicates that further low temperature oxidation pathways may be required.

\subsection{Gas-phase selectivities to minor products}

All three mechanisms underpredict the experimental $S\left(\mathrm{CO}_{2}\right)$ by $\simeq 1 \%$. The best agreement is obtained by JetSurF (-- - in Fig. 3), which predicts roughly half this value. The DTU mechanism also predicts propylene oxide $\left(\mathrm{c}-\mathrm{C}_{3} \mathrm{H}_{6} \mathrm{O}\right)$ to be a significant minor product with $S\left(\mathrm{c}-\mathrm{C}_{3} \mathrm{H}_{6} \mathrm{O}\right)$ around $8 \%$. However, propylene oxide was neither observed experimentally, ${ }^{8}$ nor predicted by Burluka and JetSurf mechanisms. The DTU mechanism contains revised propylene oxide formation pathways passing via the QOOH route that are of particular relevance to the current temperature window. 15 However, the associated destruction pathways have to date not been formulated. The Burluka and JetSurF mechanisms rely upon a simpler formation step via $\mathrm{C}_{3} \mathrm{H}_{6}+\mathrm{HO}_{2} \leftrightarrow \mathrm{c}-\mathrm{C}_{3} \mathrm{H}_{6} \mathrm{O}+\mathrm{OH}$, but include $\mathrm{c}-\mathrm{C}_{3} \mathrm{H}_{6} \mathrm{O}$ destruction pathways via ring opening towards acetone $\left(\mathrm{CH}_{3} \mathrm{C}(\mathrm{O}) \mathrm{CH}_{3}\right)$ and propionaldehyde $\left(\mathrm{CH}_{3} \mathrm{CH}_{2} \mathrm{CHO}\right)$. Propylene oxide is a liquid at room temperature and pressure, and the reactor effluent is cooled to $-5^{\circ} \mathrm{C}$ to remove water prior to the chromatographic analysis. Hence, propylene oxide may be inadvertently removed from the effluent stream. However, the reported error in the experimental carbon mass balance is $3 \%,{ }^{8}$ significantly less than the amount of propylene oxide predicted by the DTU mechanism. Inclusion of decomposition pathways of propylene oxide should ultimately lead to increased $\mathrm{CO}_{2}$ and $\mathrm{CO}$ production, 26 and improved agreement with experimental data as discussed below. It may further be noted that the catalyst may be active to propylene oxide as noted for copper-based catalysts by Xiao and Wang. 27.

\subsection{Catalysis in the propylene forming limit (M1)}

The six heterogeneous "limit" submechanisms are shown in Table 3. The first of these sequences (M1) is used to evaluate the impact of catalytic formation of propylene on the selectivities, as well as validate configuration related parameters such as the reactor porosity and the catalytic site density. The porosity 
Table 3: The six heterogeneous "limit" submechanisms in the form $A T^{\beta} e^{-E_{A} / R T}$. $\dagger$ indicates rate fitted to obtain $X\left(\mathrm{C}_{3} \mathrm{H}_{8}\right)=3.65 \%$ with $\Gamma=1.6 \times 10^{-7} \mathrm{~mol} \mathrm{~m}^{-2}$ and $20 \%$ porosity with undiluted catalyst at $40 \mathrm{ml} \mathrm{min}^{-1}$ flow.

\begin{tabular}{|c|c|c|c|c|}
\hline$\#$ & Reaction & $A(\mathrm{~m}, \mathrm{~mol}, \mathrm{~s})$ & $\beta(-)$ & $E_{A}(\mathrm{~kJ} / \mathrm{mol})$ \\
\hline M1-R15 & $\mathrm{C}_{3} \mathrm{H}_{8}+2 \mathrm{~B} s \rightarrow \mathrm{C}_{3} \mathrm{H}_{7} s+\mathrm{H} s$ & $\dagger 5.64 \times 10^{-4}$ & 0.5 & 0 \\
\hline M1-R16 & $\mathrm{C}_{3} \mathrm{H}_{7} \mathrm{~s} \rightarrow \mathrm{C}_{3} \mathrm{H}_{6}+\mathrm{Hs}$ & $1 \times 10^{13}$ & 0 & 0 \\
\hline M2-R15 & $\mathrm{C}_{3} \mathrm{H}_{8}+2 \mathrm{O} s \rightarrow \mathrm{C}_{3} \mathrm{H}_{7} \mathrm{O} s+\mathrm{OH} s$ & $\dagger 4.61 \times 10^{-7}$ & 0.5 & 0 \\
\hline M2-R16 & $\mathrm{C}_{3} \mathrm{H}_{7} \mathrm{Os} \rightarrow \mathrm{C}_{3} \mathrm{H}_{6}+\mathrm{OH} s$ & $1 \times 10^{13}$ & 0 & 0 \\
\hline M3-R15 & $\mathrm{C}_{3} \mathrm{H}_{8}+2 \mathrm{O} s \rightarrow \mathrm{C}_{3} \mathrm{H}_{7} \mathrm{O} s+\mathrm{OH} s$ & $\dagger 2.79 \times 10^{-7}$ & 0.5 & 0 \\
\hline M3-R16i & $\mathrm{C}_{3} \mathrm{H}_{7} \mathrm{Os} \rightarrow \mathrm{i}-\mathrm{C}_{3} \mathrm{H}_{7} \mathrm{O}+\mathrm{B} s$ & $2 \times 10^{13}$ & 0 & 20.9 \\
\hline M3-R16n & $\mathrm{C}_{3} \mathrm{H}_{7} \mathrm{Os} \rightarrow \mathrm{n}-\mathrm{C}_{3} \mathrm{H}_{7} \mathrm{O}+\mathrm{Bs}$ & $6 \times 10^{13}$ & 0 & 3.4 \\
\hline M4-R15 & $\mathrm{C}_{3} \mathrm{H}_{8}+2 \mathrm{~B} s \rightarrow \mathrm{C}_{3} \mathrm{H}_{7} s+\mathrm{H} s$ & $\dagger 3.81 \times 10^{-4}$ & 0.5 & 0 \\
\hline M4-R16i & $\mathrm{C}_{3} \mathrm{H}_{7} \mathrm{~s} \rightarrow \mathrm{i}-\mathrm{C}_{3} \mathrm{H}_{7}+\mathrm{B} s$ & $2 \times 10^{13}$ & 0 & 31.4 \\
\hline M4-R16n & $\mathrm{C}_{3} \mathrm{H}_{7} \mathrm{~s} \rightarrow \mathrm{n}-\mathrm{C}_{3} \mathrm{H}_{7}+\mathrm{Bs}$ & $6 \times 10^{13}$ & 0 & 20.9 \\
\hline M5-R15 & $\mathrm{C}_{3} \mathrm{H}_{8}+2 \mathrm{O} s \rightarrow \mathrm{C}_{3} \mathrm{H}_{7} \mathrm{O} s+\mathrm{OH} s$ & $\dagger 2.65 \times 10^{-7}$ & 0.5 & 0 \\
\hline M5-R16 & $\mathrm{C}_{3} \mathrm{H}_{7} \mathrm{Os} \rightarrow \mathrm{C}_{2} \mathrm{H}_{4}+\mathrm{CH}_{3}+\mathrm{Os}$ & $1 \times 10^{13}$ & 0 & 0 \\
\hline M6-R15 & $\mathrm{C}_{3} \mathrm{H}_{8}+2 \mathrm{O} s \rightarrow \mathrm{C}_{3} \mathrm{H}_{7} \mathrm{O} s+\mathrm{OH} s$ & $\dagger 4.74 \times 10^{-7}$ & 0.5 & 0 \\
\hline M6-R16 & $\mathrm{C}_{3} \mathrm{H}_{7} \mathrm{Os} \rightarrow \mathrm{C}_{2} \mathrm{H}_{6}+\mathrm{CO}+\mathrm{B} s$ & $1 \times 10^{13}$ & 0 & 0 \\
\hline
\end{tabular}

of the reactor affects the residence time and we apply the literature values ${ }^{8}$ in the first three sections (see Fig. 1). To validate our plug-flow reactor model, we determine the impact of porosity of the last section on the overall conversion due to residence time effects in the heated section. For this purpose, the DTU gas-phase mechanism is coupled to the catalytic chemistry shown in Table 1 and extended by sequence M1 as shown below.

$$
\begin{aligned}
& \mathrm{M} 1-\mathrm{R} 15: \mathrm{C}_{3} \mathrm{H}_{8}+2 \mathrm{~B} s \rightarrow \mathrm{C}_{3} \mathrm{H}_{7} s+\mathrm{H} s, \quad A=5.64 \times 10^{-4} \mathrm{~m}^{3} \mathrm{~mol}^{-1} \mathrm{~s}^{-1}, \quad \beta=0.5, \quad E_{A}=0 \\
& \mathrm{M} 1-\mathrm{R} 16: \mathrm{C}_{3} \mathrm{H}_{7} s \rightarrow \mathrm{C}_{3} \mathrm{H}_{6}+\mathrm{H} s, \quad A=1.0 \times 10^{13} \mathrm{~s}^{-1}, \quad \beta=0, \quad E_{A}=0
\end{aligned}
$$

The desorption in M1-R16 is unlikely to be barrierless. However, setting a barrier height has no effect if M1-R16 is not rate limiting as there is no alternative outlet for $\mathrm{C}_{3} \mathrm{H}_{7} s$. Under such circumstances, the pre-exponential of M1-R15 can be fitted to match the observed conversion. The conversion reported in the control experiments without $\mathrm{hBN}$ is $X\left(\mathrm{C}_{3} \mathrm{H}_{8}\right)=1 \%$ at $550^{\circ} \mathrm{C}$ and $0.3 \%$ at $500^{\circ} \mathrm{C}$ with the latter value indicated in Fig. 4 by the open circle (o). We note again that in the experiments, the temperature of the furnace is controlled by a single thermocouple embedded in the catalytic bed. $\mathbb{8}^{\text {This }}$ low level of conversion is only matched when the porosity of the rear section is around $1 \%$, an unusually low value 
given that the porosity of the $\mathrm{SiO}_{2}$ wool is $40 \%$ and the porosity of $\mathrm{SiO}_{2}$ chips has been reported as high as 50\%. ${ }^{28}$ In the following, we tentatively apply an intermediate value of porosity of $20 \%$, corresponding to a conversion of $0.9 \%$ in the control experiment.

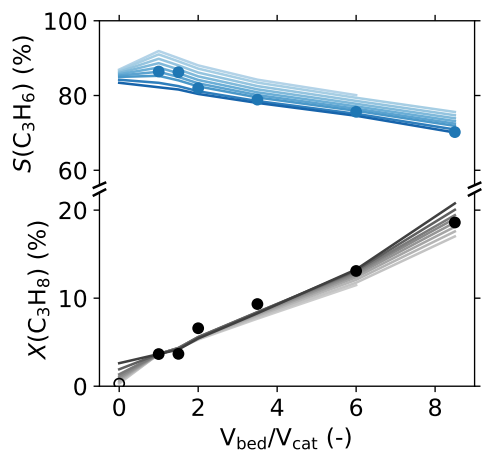

Figure 4: Effect of porosity on the propane conversion and propylene selectivity, with the pre-exponential of R15-1 fitted to match conversion for undiluted case. Shading implies porosity in the range of 1-50\%.

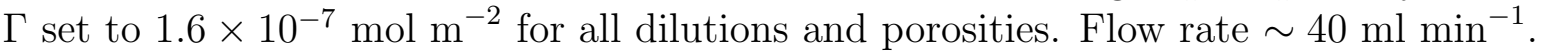

In addition to the porosity of the last section of the reactor and the adsorption rate constant M1-R15, $X\left(\mathrm{C}_{3} \mathrm{H}_{8}\right)$ is also a function of the site density $\Gamma$. The physical constraint on the site density of hBN is $\Gamma \leq 3.04 \times 10^{-5} \mathrm{~mol} \mathrm{~m}^{-2}$, derived from a theoretical unit cell area of $5.462 \AA^{2}$ per boron site. $\frac{29]}{\text { The }}$ $\Gamma$ used throughout the current work is fitted together with the pre-exponential of M1-R15 to ensure $X\left(\mathrm{C}_{3} \mathrm{H}_{8}\right)=3.65 \%$ for the undiluted case, and $18.60 \%$ for $V_{\text {bed }} / V_{\text {cat }}=8.5$, given a porosity of $20 \%$ in the last section of the reactor, shown in Fig. 4. The resulting values are $A_{\mathrm{M} 1-\mathrm{R} 15}=5.64 \times 10^{-4} \mathrm{~m}^{3} \mathrm{~mol}^{-1} \mathrm{~s}^{-1}$ and $\Gamma=1.6 \times 10^{-7} \mathrm{~mol} \mathrm{~m}{ }^{-2}$ corresponding to $0.5 \%$ availability of boron sites with respect to the theoretical maximum.

The above two-step process is a limiting case. It is much more likely the actual propane activation process involves reversible $\mathrm{C}_{3} \mathrm{H}_{8}$ adsorption followed by a $\mathrm{C}-\mathrm{H}$ bond activation on the surface with an appreciable barrier. The dissociative adsorption described by M1-R15 can accordingly be thought of as a global reaction step with an exceptionally low sticking coefficient $\left(s_{0} \sim 10^{-12}\right)$ when compared to $s_{0}=5.8 \times 10^{-3}$ for $\mathrm{C}_{3} \mathrm{H}_{8}$ on rhodium. $\stackrel{30}{30}$ To obtain the same rate constant at $500^{\circ} \mathrm{C}$, assuming the same propane sticking coefficient as on rhodium, the dissociative adsorption would have to proceed with a barrier of $117 \mathrm{~kJ} / \mathrm{mol}$. The barrier appears high, but is well below the reported experimental apparent activation energies for ODH of propane $(184-233 \mathrm{~kJ} / \mathrm{mol} \stackrel{225}{25})$. For comparison, on vanadium oxides, dissociative adsorption of propane was calculated to proceed with a barrier of $144-151 \mathrm{~kJ} / \mathrm{mol}$. 31 . 


\subsection{Catalysis in the Eley-Rideal mediated propylene forming limit (M2)}

The second (M2) limiting mechanism features an $\mathrm{O} s$-mediated Eley-Rideal type $\mathrm{C}_{3} \mathrm{H}_{6}$ forming mechanism as proposed by Shi et al. ${ }^{7}$. The mechanism is consistent with the presence of surface oxygen in $\mathrm{X}$-ray photoelectron spectra (XPS) ${ }^{115}$ as well as B-OH vibrations in infrared spectra. ${ }^{1732}$ The applied rate constants are listed in Table 3. The adsorption rate (M2-R15) has again been fitted to match the conversion in the undiluted case, which allowed us to apply a barrierless desorption step, as the adsorption is rate limiting.
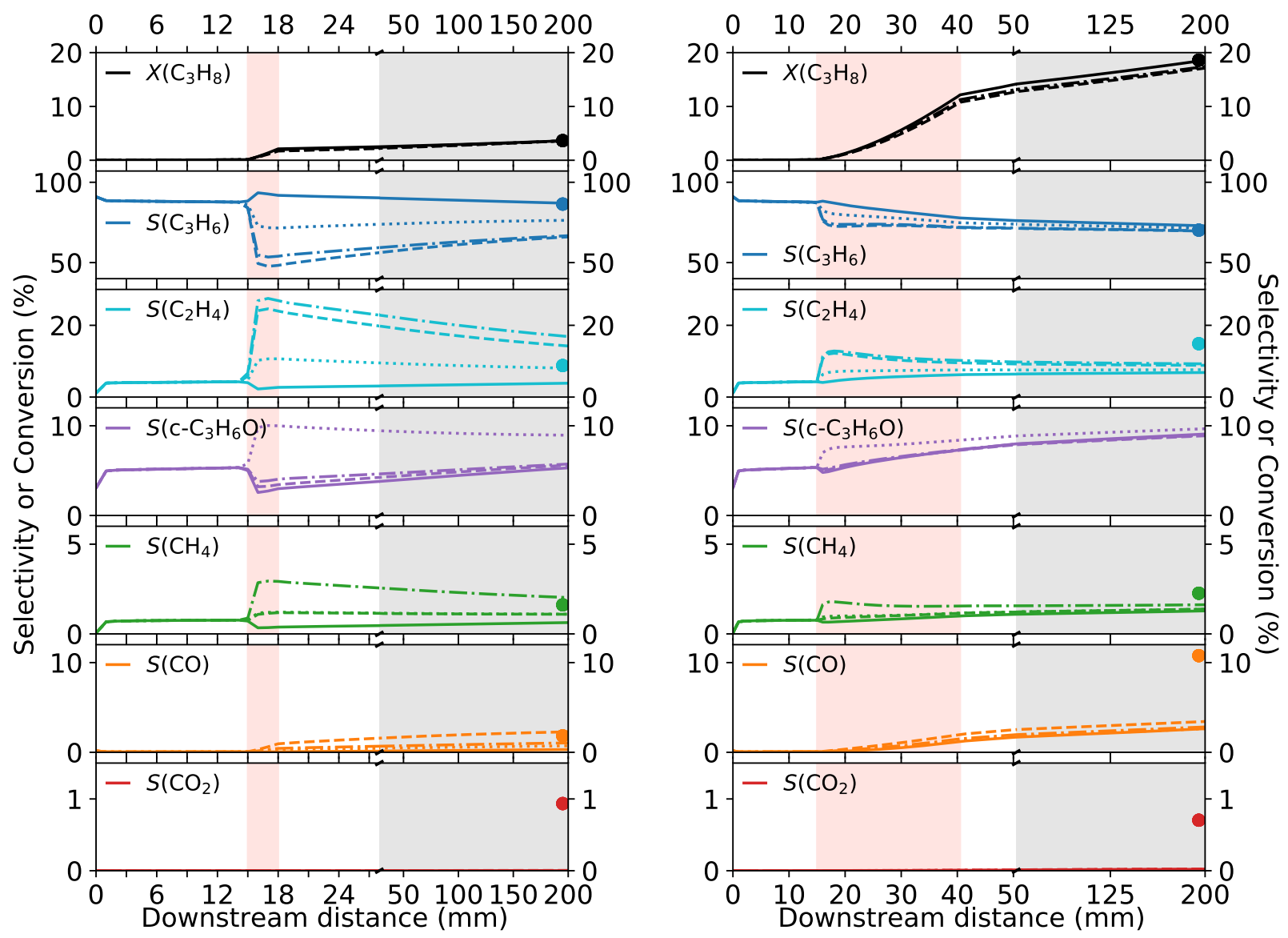

Figure 5: Selectivities $(S)$ and conversion $(X)$ of selected species as a function of downstream distance with four of the six limit mechanisms: M1: direct $\mathrm{C}_{3} \mathrm{H}_{6}(-)$, M3: Os-mediated $\mathrm{C}_{3} \mathrm{H}_{7} \mathrm{O}(---)$, M4: direct $\mathrm{C}_{3} \mathrm{H}_{7}(\cdots \cdots)$, and $\mathrm{M} 5$ : Os-mediated $\mathrm{C}-\mathrm{C}$ scission (-.. ). Case with an undiluted catalyst (left) and with the highest dilution $\left(V_{\text {bed }} / V_{\text {cat }}=8.5\right.$, right $)$, both at $\sim 40 \mathrm{ml} \mathrm{min}^{-1}$. Lines are calculated data, circles are experimental results, ${ }^{8}$ shaded areas correspond to the front and rear heat shield (white), the catalytic zone (red), and $\mathrm{SiO}_{2}$ chips (gray).

The direct $\mathrm{C}_{3} \mathrm{H}_{6}$ mechanism (M1, - in Fig. 5) and the Os-mediated $\mathrm{C}_{3} \mathrm{H}_{6}$ mechanism (M2, not shown) show nearly identical selectivity and conversion profiles, despite the different nature of $\mathrm{C}_{3} \mathrm{H}_{8}$ 
activation on the catalytic surface. The pre-exponentials of the adsorption steps in the two mechanisms differ by around a factor of $10^{3}$ with the $\mathrm{O} s$-mediated M2 mechanism being the more active (i.e. a reduction in the pre-exponential factor is required to meet the target conversion). The predicted surface coverages of $\mathrm{B} s$ and $\mathrm{O} s$ are $1.8 \%$ and $98.2 \%$ after the first $\mathrm{mm}$ and $2.8 \%$ and $97.1 \%$ after the last $\mathrm{mm}$ of the undiluted catalyst, respectively. When the effect of surface coverages on the rate laws is taken into account, the Eley-Rideal pathway leads to a $5 / 2$ faster propane adsorption rate at the beginning of the catalytic section. However, both mechanisms quickly converge to the same adsorption rate in the last $\mathrm{mm}$ of the catalyst, yielding indistinguishable conversion profiles. The availability of free $(\mathrm{B} s)$ and $\mathrm{O} s$ sites is therefore not limiting in the current model. A small proportion of sites $(0.06 \%$ in undiluted, $0.1 \%$ in diluted cases) is covered by $\mathrm{OH} s$, regardless of the adsorption pathway. The presence of $\mathrm{OH} s$ is consistent with analysis of the spent catalysts, but it is not conclusive proof of an Eley-Rideal mechanism, as the adsorption of propane may equally plausibly proceed on exposed $\mathrm{B} s$ or $\mathrm{O} s$ sites, and the $\mathrm{B}-\mathrm{OH}$ species can be explained by either abstraction of the second $\mathrm{H}$ by $\mathrm{O} s$ leading to $\mathrm{C}_{3} \mathrm{H}_{6}$ formation, or by a surface reaction between $\mathrm{H} s$ and $\mathrm{O} s$. The predicted surface coverages may change once multiple branching pathways are introduced, and once the $\mathrm{H} / \mathrm{O}$ submechanism is validated for $\mathrm{hBN}$.

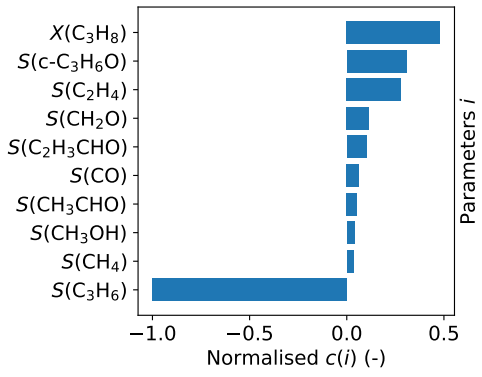

Figure 6: Normalised sensitivity coefficients $c(i)$ of parameters $i$ with respect to the $\mathrm{O}_{2}$ adsorption rate for reaction (R4) in the $\mathrm{H} / \mathrm{O}$ submechanism from Deutschmann et al. $\underline{20}$

The $\mathrm{H} / \mathrm{O}$ submechanism, developed for platinum, is taken verbatim from Deutschmann et al. ${ }^{20}$ As we have adjusted $\Gamma$, a sensitivity analysis on the rate of $\mathrm{O}_{2}$ dissociative adsorption (R4) was performed by varying the pre-exponential factor $\left(A_{R 4}\right)$ by an order of magnitude between $1.8 \times 10^{8}-1.8 \times$ $10^{10} \mathrm{~m}^{6} \mathrm{~mol}^{-2} \mathrm{~s}^{-1}$. The largest absolute sensitivity coefficient is $c\left(S\left(\mathrm{C}_{3} \mathrm{H}_{6}\right)\right)=\partial S\left(\mathrm{C}_{3} \mathrm{H}_{6}, A_{\mathrm{R} 4}\right) / \partial A_{\mathrm{R} 4}$ with value on the order of $10^{-2}$, which indicates the $\mathrm{H} / \mathrm{O}$ chemistry is significantly contributing to the sur- 
face chemistry. The normalised coefficients of the 10 most sensitive parameters are shown in Figure 6 : $X\left(\mathrm{C}_{3} \mathrm{H}_{8}\right)$ and selectivities to minor species correlate positively with $A_{\mathrm{R} 4}$, while $S\left(\mathrm{C}_{3} \mathrm{H}_{6}\right)$ correlates negatively. In a rigorous approach to mechanism development, the $\mathrm{H} / \mathrm{O}$ submechanism would have to be tailored to account for the differences between Pt and hBN. Figure 6 shows that a further increase in the ratio of the effective sticking probabilities of $\mathrm{O}_{2}$ and $\mathrm{C}_{3} \mathrm{H}_{6}$ would lead to a higher activity of the catalyst and lower selectivity to propylene.

As shown in Fig. 5, the M1 and M2 mechanisms are unsurprisingly the most selective towards $\mathrm{C}_{3} \mathrm{H}_{6}(-)$. The downstream profiles show only a small amount of post-catalytic combustion of the main product (gray shading). However, similarly to the gas-phase results, the selectivities towards $\mathrm{C}_{2} \mathrm{H}_{4}(-)$ and $\mathrm{CO}(-)$ are underpredicted, especially in diluted catalytic beds $(\Delta \sim 8 \%)$. This may be a consequence of the high selectivity towards propylene oxide $\left(\mathrm{c}-\mathrm{C}_{3} \mathrm{H}_{6} \mathrm{O},-, 9.0 \%\right)$, acrolein $\left(\mathrm{C}_{2} \mathrm{H}_{3} \mathrm{CHO}, 3.3 \%\right)$ and formaldehyde $\left(\mathrm{CH}_{2} \mathrm{O}, 1.9 \%\right)$, neither of which has been recorded experimentally. When compared to the gas-phase $S$ vs $X$ results (Fig. 3), the addition of the surface pathways decreases the agreement with experiment. Therefore, while $\mathrm{C}_{3} \mathrm{H}_{6}$ may be produced on the surface, it is unlikely to be the only catalytic product as proposed by Shi et al. ${ }^{7}$

\subsection{Catalysis in the radical forming limit (M3 and M4)}

The initially proposed mechanism for the activity of hBN (M3) involves adsorption on oxygen-covered boron sites and leading to the formation of propoxy radicals $\left(\mathrm{C}_{3} \mathrm{H}_{7} \mathrm{O}\right)$. [1] We also include the direct,

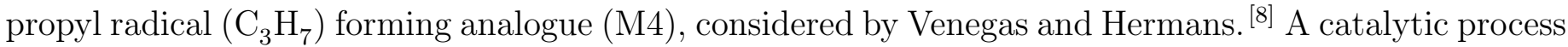
where propyl radicals desorb rather than undergo further $\mathrm{H}$-abstraction to propylene on the surface seems unlikely. Venegas et al. $\stackrel{9}{ }$ recently proposed a mechanism where surface-bound oxygen $(\mathrm{O} s)$ abstracts hydrogen from propane leading to $\mathrm{C}_{3} \mathrm{H}_{7}$ isomers via a barrierless process. Here, we include the propyl forming mechanism to probe the potential impact that additional propyl radicals would have on the gas-phase behaviour. The rate constants are listed in Table 3. Rather than overfitting the models by using six parameters in each of the two mechanisms, we have opted to fit only the adsorption preexponential terms (M3-R15 and M4-R15) to match the observed conversion. The adsorption steps are therefore rate limiting. The pre-exponential factors for the desorption step are branched to iso- and 
n-propoxy (or propyl) radicals, and the order of magnitude estimates are scaled 2:6 to account for the number of equivalent hydrogens in propane. The barrier heights for product desorption are taken from similar gas-phase reactions in the DTU mechanism. As the reference experiments have been carried out at a single temperature, and the adsorption step is enforced to be rate limiting, the choice of the desorption barrier heights is arbitrary.

The two mechanisms show a very different behaviour when considered in isolation as well as when compared to the propylene forming limit cases (M1 and M2). In the undiluted case, the propoxy mechanism (--- ) results in a significantly higher amount of $\mathrm{C}-\mathrm{C}$ scission than the propyl mechanism $(\cdots . .$.$) . The selectivity to the main product, propylene, is significantly underpredicted by both of these$ mechanisms, and it is dropping in the catalytic zone (red area) of the reactor. The mechanism based on $\mathrm{C}_{3} \mathrm{H}_{7} \mathrm{O}$ isomers underpredicts $S\left(\mathrm{C}_{3} \mathrm{H}_{6}\right)$ by over $20 \%(---)$, while overpredicting $S\left(\mathrm{C}_{2} \mathrm{H}_{4}\right)$ by $6 \%(--$ ), and $\mathrm{CO}(--)$ by $0.6 \%$. By contrast, in the undiluted case the mechanism featuring $\mathrm{C}_{3} \mathrm{H}_{7}$ isomers underpredicts $S\left(\mathrm{C}_{3} \mathrm{H}_{6}\right)$ to a smaller degree $(\cdots \cdots)$, and it predicts the correct amount of $\mathrm{C}_{2} \mathrm{H}_{4}(\cdots \cdots)$. However, the selectivity to propylene oxide (......) is nearly double that of the other mechanisms studied, as the propyl radicals are clearly forming propylene oxide in the gas-phase upon (the unlikely) desorption from the catalyst. Finally, upon dilution of the catalytic bed, both mechanisms converge towards the values predicted for the M1 and M2 mechanisms as the gas-phase chemistry pushes the selectivities towards equilibrium. Both mechanisms also predict $\mathrm{c}-\mathrm{C}_{3} \mathrm{H}_{6} \mathrm{O}$ and $\mathrm{C}_{2} \mathrm{H}_{3} \mathrm{CHO}$ selectivities similar to the $\mathrm{M} 1$ and $\mathrm{M} 2$ mechanisms, with the $\mathrm{C}_{3} \mathrm{H}_{7} \mathrm{O}$ pathways yielding the highest amount of $\mathrm{CH}_{2} \mathrm{O}(2.8 \%)$.

\subsection{Catalysis in the $\mathrm{C}-\mathrm{C}$ scission limit (M5 and M6)}

The final two limit mechanisms studied here are two-step models leading to either $\mathrm{C}_{2} \mathrm{H}_{4}$ and $\mathrm{CH}_{3}$ formation (M5), or $\mathrm{C}_{2} \mathrm{H}_{6}$ and $\mathrm{CO}$ formation (M6), both proceeding via $\mathrm{O} s$-mediated adsorption, see Table 3. From the multitude of possible saturated, unsaturated, or oxygenated $\mathrm{C}-\mathrm{C}$ scission products, we chose the above two combinations to directly stimulate $\mathrm{C}_{2} \mathrm{H}_{4}$ and $\mathrm{CH}_{4}(\mathrm{M} 5)$ or $\mathrm{CO}$ (M6) production. We note that detailed heterogeneous microkinetic mechanisms for $\mathrm{C}_{3}$ species that also include $\mathrm{C}_{2}$ products are rather rare: the above mentioned mechanism for propane partial oxidation over rhodium ${ }^{30}$ only contains desorption pathways for $\mathrm{C}_{3} \mathrm{H}_{8}, \mathrm{CO}, \mathrm{CO}_{2}$, and $\mathrm{CH}_{4}$; the mechanism for propane $\mathrm{ODH}$ over 
vanadium oxide catalysts is more complete ${ }^{31}$ but has, to our knowledge, not been evaluated together with gas-phase chemistry. As in previous cases, the rate constants of the adsorption processes (M5-R15, M6-R16) are fitted to match the experimental conversion and therefore are rate limiting.

When the surface chemistry is fully shifted towards $\mathrm{C}_{2} \mathrm{H}_{4}$ and $\mathrm{CH}_{3}$ (M5, -.. ), the selectivities to $S\left(\mathrm{C}_{2} \mathrm{H}_{4}\right)(\cdots)$ and $S\left(\mathrm{CH}_{4}\right)(\cdots)$ exceed the experimental values for the undiluted case. Tian et al. suggested a catalytic $\mathrm{C}-\mathrm{C}$ scission would lead to a $1: 1 \mathrm{C}_{2}: \mathrm{C}_{1}$ distribution in products while a higher ratio of $2: 1$ is observed experimentally in the undiluted case. ${ }^{8}$ The authors proposed a catalytic $\mathrm{CH}_{3}$-coupling process as a way of accounting for this discrepancy. ${ }^{33}$ Here, we obtain an overall $\mathrm{C}_{2}: \mathrm{C}_{1}$ ratio of 1.67 with the oxygen mediated $\mathrm{C}_{3} \mathrm{H}_{6}$ forming mechanism (M2) and ratios above 1.90 with both $\mathrm{C}-\mathrm{C}$ scission mechanisms. For the undiluted cases, catalytic $\mathrm{C}-\mathrm{C}$ scission unsurprisingly leads to higher $\mathrm{C}_{2}$ : $\mathrm{C}_{1}$ ratios than mechanisms without surface $\mathrm{C}-\mathrm{C}$ bond scission. The experimental $\mathrm{C}_{2}: \mathrm{C}_{1}$ ratios can be matched without $\mathrm{CH}_{3}$-coupling surface reactions. In all other aspects, the $\mathrm{C}_{2} \mathrm{H}_{4}$ and $\mathrm{CH}_{3}$ mechanism (M5) is very similar to the M3 mechanism corresponding to the $\mathrm{i}-\mathrm{C}_{3} \mathrm{H}_{7} \mathrm{O}$ and $\mathrm{n}-\mathrm{C}_{3} \mathrm{H}_{7} \mathrm{O}$ forming limit (--- ). On the other hand, the $\mathrm{C}_{2} \mathrm{H}_{6}$ and $\mathrm{CO}$ forming limit (M6, not shown) performs rather poorly, as $S\left(\mathrm{C}_{3} \mathrm{H}_{6}\right)$ is undepredicted by over $30 \%, S(\mathrm{CO})$ is overpredicted by $10 \%$, and most of the $22 \%$ of $\mathrm{C}_{2} \mathrm{H}_{6}$ produced on the surface does not dehydrogenate towards $\mathrm{C}_{2} \mathrm{H}_{4}$ in the gas phase. It is therefore unlikely that $\mathrm{CO}$ is formed via direct oxidation of $\mathrm{C}_{3} \mathrm{H}_{8}$ on the surface, or that $\mathrm{C}_{2} \mathrm{H}_{6}$ is formed by the catalyst.

Upon dilution of the catalytic bed, convergence of both $\mathrm{C}-\mathrm{C}$ scission pathways with the other four mechanisms (M1-M4) can be observed, leading to a significant underprediction of selectivities to $S\left(\mathrm{C}_{2} \mathrm{H}_{4}\right)$ $(\cdots, \Delta=5 \%)$ and $S(\mathrm{CO})(\cdots, \Delta=8 \%)$ even with $\mathrm{C}_{2} \mathrm{H}_{4}$ or $\mathrm{CO}$ formed catalytically on the surface. This behaviour is accompanied by a high selectivity to experimentally undetected products $\mathrm{c}^{-} \mathrm{C}_{3} \mathrm{H}_{6} \mathrm{O}$, $\mathrm{C}_{2} \mathrm{H}_{3} \mathrm{CHO}$ and $\mathrm{CH}_{2} \mathrm{O}$.

\subsection{Impact of propylene oxide chemistry on selectivities}

As discussed above, the selectivity towards propylene oxide calculated with the DTU mechanism appears at variance with experimental data. The low temperature chemistry of propylene oxide is hence likely to require further work. By contrast, the propylene oxide chemistry in the JetSurF mechanism is based on the high temperature shock temperature work by Lifshitz and Tamburu ${ }^{34}$. This mechanism was 
later expanded by Burluka et al. $\frac{13}{3}$ and the resulting $\mathrm{c}-\mathrm{C}_{3} \mathrm{H}_{6} \mathrm{O}$ submechanism is listed in Table 4 . We note that the $\mathrm{c}-\mathrm{C}_{3} \mathrm{H}_{6} \mathrm{O}$ and $\mathrm{C}_{2} \mathrm{H}_{3} \mathrm{CHO}$ pathways are not directly coupled and inclusion of the hightemperature decomposition pathways into the DTU mechanism does not impact the selectivities at high bed dilutions. However, the conversion of propane goes down appreciably from $18.5 \%$ to $16.7 \%$.

Table 4: Propylene oxide formation and decomposition pathways from Burluka et al. $\underline{13}$ with rate parameters in the form $A T^{\beta} e^{-E_{A} / R T}$.

\begin{tabular}{|c|c|c|c|}
\hline Reaction & $A(\mathrm{~m}, \mathrm{~mol}, \mathrm{~s})$ & $\beta(-)$ & $E_{A}(\mathrm{~kJ} / \mathrm{mol})$ \\
\hline $\mathrm{C}_{3} \mathrm{H}_{6}+\mathrm{HO}_{2} \leftrightarrow \mathrm{c}-\mathrm{C}_{3} \mathrm{H}_{6} \mathrm{O}+\mathrm{OH}$ & $1.05 \times 10^{6}$ & 0.0 & 59.46 \\
\hline $\mathrm{C}_{3} \mathrm{H}_{6}+\mathrm{CH}_{3} \mathrm{OO} \leftrightarrow \mathrm{c}-\mathrm{C}_{3} \mathrm{H}_{6} \mathrm{O}+\mathrm{CH}_{3} \mathrm{O}$ & $4.00 \times 10^{5}$ & 0.0 & 49.04 \\
\hline $\mathrm{CH}_{3} \mathrm{CH}_{2} \mathrm{OO}+\mathrm{C}_{3} \mathrm{H}_{6} \leftrightarrow \mathrm{cC}_{3} \mathrm{H}_{6} \mathrm{O}+\mathrm{CH}_{3} \mathrm{CH}_{2} \mathrm{O}$ & $8.05 \times 10^{5}$ & 0.0 & 67.78 \\
\hline $\mathrm{C}_{3} \mathrm{H}_{6}+\mathrm{CH}_{2} \mathrm{CHCH}_{2} \mathrm{OO} \leftrightarrow \mathrm{c}-\mathrm{C}_{3} \mathrm{H}_{6} \mathrm{O}+\mathrm{c}-\mathrm{C}_{3} \mathrm{H}_{5} \mathrm{O}$ & $1.05 \times 10^{5}$ & 0.0 & 59.41 \\
\hline $\mathrm{C}_{3} \mathrm{H}_{6}+\mathrm{n}-\mathrm{C}_{3} \mathrm{H}_{7} \mathrm{OO} \leftrightarrow \mathrm{c}-\mathrm{C}_{3} \mathrm{H}_{6} \mathrm{O}+\mathrm{n}-\mathrm{C}_{3} \mathrm{H}_{7} \mathrm{O}$ & $1.05 \times 10^{1}$ & 0.0 & 0.0 \\
\hline $\mathrm{c}-\mathrm{C}_{3} \mathrm{H}_{6} \mathrm{O} \leftrightarrow \mathrm{C}_{2} \mathrm{H}_{5}+\mathrm{HCO}$ & $2.45 \times 10^{13}$ & 0.0 & 244.80 \\
\hline $\mathrm{c}-\mathrm{C}_{3} \mathrm{H}_{6} \mathrm{O} \leftrightarrow \mathrm{CH}_{3} \mathrm{CH}_{2} \mathrm{CHO}$ & $1.82 \times 10^{14}$ & 0.0 & 244.80 \\
\hline $\mathrm{c}-\mathrm{C}_{3} \mathrm{H}_{6} \mathrm{O} \leftrightarrow \mathrm{CH}_{3}+\mathrm{CH}_{3} \mathrm{CO}$ & $4.54 \times 10^{13}$ & 0.0 & 250.60 \\
\hline $\mathrm{c}-\mathrm{C}_{3} \mathrm{H}_{6} \mathrm{O} \leftrightarrow \mathrm{CH}_{3}+\mathrm{CH}_{2} \mathrm{CHO}$ & $2.45 \times 10^{13}$ & 0.0 & 246.10 \\
\hline $\mathrm{c}-\mathrm{C}_{3} \mathrm{H}_{6} \mathrm{O} \leftrightarrow \mathrm{CH}_{3}+\mathrm{c}-\mathrm{C}_{2} \mathrm{H}_{3} \mathrm{O}$ & $8.00 \times 10^{15}$ & 0.0 & 384.97 \\
\hline $\mathrm{c}-\mathrm{C}_{3} \mathrm{H}_{6} \mathrm{O}+\mathrm{H} \leftrightarrow \mathrm{H}_{2}+\mathrm{CH}_{2} \mathrm{CO}+\mathrm{CH}_{3}$ & $2.70 \times 10^{1}$ & 2.0 & 20.92 \\
\hline $\mathrm{c}-\mathrm{C}_{3} \mathrm{H}_{6} \mathrm{O}+\mathrm{O} \leftrightarrow \mathrm{OH}+\mathrm{HCO}+\mathrm{C}_{2} \mathrm{H}_{4}$ & $7.80 \times 10^{7}$ & 0.0 & 21.80 \\
\hline $\mathrm{c}-\mathrm{C}_{3} \mathrm{H}_{6} \mathrm{O}+\mathrm{OH} \leftrightarrow \mathrm{H}_{2} \mathrm{O}+\mathrm{CH}_{2} \mathrm{CO}+\mathrm{CH}_{3}$ & $7.80 \times 10^{0}$ & 2.0 & -3.20 \\
\hline $\mathrm{c}-\mathrm{C}_{3} \mathrm{H}_{6} \mathrm{O}+\mathrm{HO}_{2} \leftrightarrow \mathrm{CH}_{2} \mathrm{CO}+\mathrm{CH}_{3}+\mathrm{H}_{2} \mathrm{O}_{2}$ & $1.20 \times 10^{6}$ & 0.0 & 64.85 \\
\hline $\mathrm{c}-\mathrm{C}_{3} \mathrm{H}_{6} \mathrm{O}+\mathrm{CH}_{3} \leftrightarrow \mathrm{CH}_{2} \mathrm{CO}+\mathrm{CH}_{3}+\mathrm{CH}_{4}$ & $6.00 \times 10^{5}$ & 0.0 & 40.20 \\
\hline $\mathrm{c}-\mathrm{C}_{3} \mathrm{H}_{6} \mathrm{O}+\mathrm{CH}_{3} \mathrm{OO} \leftrightarrow \mathrm{CH}_{3} \mathrm{OOH}+\mathrm{CH}_{2} \mathrm{CO}+\mathrm{CH}_{3}$ & $6.00 \times 10^{5}$ & 0.0 & 40.20 \\
\hline $\mathrm{c}-\mathrm{C}_{3} \mathrm{H}_{6} \mathrm{O}+\mathrm{C}_{2} \mathrm{H}_{5} \leftrightarrow \mathrm{C}_{2} \mathrm{H}_{5}+\mathrm{CH}_{2} \mathrm{CO}+\mathrm{CH}_{3}$ & $6.00 \times 10^{5}$ & 0.0 & 46.02 \\
\hline
\end{tabular}

In view of the incomplete low temperature propylene oxide chemistry, a different approach is to replace the $\mathrm{c}-\mathrm{C}_{3} \mathrm{H}_{6} \mathrm{O}$ pathways in the DTU mechanism with that shown in Table 4 . This modified mechanism is denoted DTU/B. As shown in Fig. 7, the gas-phase selectivity to propylene oxide drops (--- ), and is compensated mainly by an increase in $S\left(\mathrm{C}_{3} \mathrm{H}_{6}\right)$ (-- ) and a small increase in $S(\mathrm{CO})$ (-- ) at higher conversions. When the two mechanisms are coupled with the Eley-Rideal propylene limit mechanism (M2), the amount of $\mathrm{c}-\mathrm{C}_{3} \mathrm{H}_{6} \mathrm{O}$ formed is appreciably reduced $(\Delta=-5.42 \%)$, with the selectivities to $\mathrm{C}_{2} \mathrm{H}_{4}(\Delta=+0.22 \%), \mathrm{CO}(\Delta=+0.34 \%)$, and especially $\mathrm{C}_{3} \mathrm{H}_{6}(\Delta=+3.95 \%)$ increasing accordingly as shown in Fig 8, The modification of the DTU mechanism therefore improves the agreement with experiment significantly. However, the discrepancies in $S\left(\mathrm{C}_{2} \mathrm{H}_{4}\right)$ and especially $S(\mathrm{CO})$ remain.

A further possible explanation for the lack of experimentally observed $c-\mathrm{C}_{3} \mathrm{H}_{6} \mathrm{O}$ may be due to its catalytic decomposition towards $\mathrm{C}-\mathrm{C}$ scission products. Xiao and Wang investigated $\mathrm{c}-\mathrm{C}_{3} \mathrm{H}_{6} \mathrm{O}$ forma- 


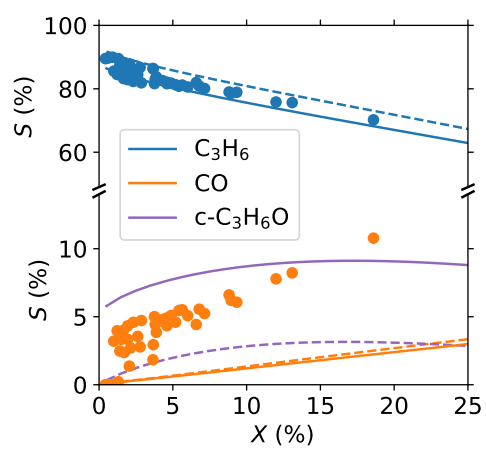

Figure 7: Effect of $\mathrm{c}-\mathrm{C}_{3} \mathrm{H}_{6} \mathrm{O}$ chemistry on the gas-phase selectivity vs conversion behaviour. The unmodified DTU mechanism (- ) is compared to the DTU/B mechanism (-- - ) containing $\mathrm{c}-\mathrm{C}_{3} \mathrm{H}_{6} \mathrm{O}$ formation and destruction pathways from Burluka et al. 13 listed in Table 4. Same conditions as in Fig. 3

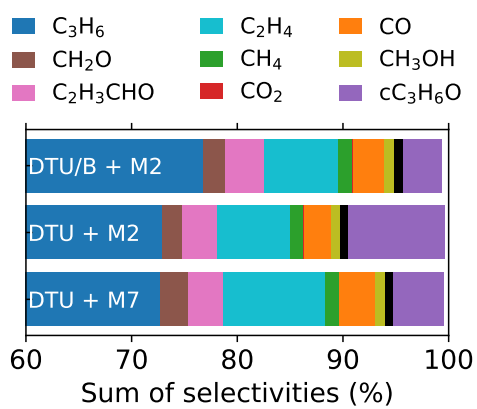

Figure 8: The effect of propylene oxide decomposition pathways on the selectivities. Shown for $V_{\text {bed }} / V_{\text {cat }}=8.5$ at $\sim 40 \mathrm{ml} / \mathrm{min}$ flow rate, with gas-phase and heterogeneous mechanisms as indicated.

tion pathways from propylene on $\mathrm{Cu}$ surfaces using density functional theory, proposing an oxygenated metallacyclic intermediate as the key intermediate. ${ }^{27}$ We note one of these intermediates could plausibly decompose towards $\mathrm{CH}_{2} \mathrm{O}$ and $\mathrm{C}_{2} \mathrm{H}_{4}$ following a single $\mathrm{H}$-shift and explore this possibility by augmenting the M2 mechanism by two speculative pathways denoted as M7.

$$
\begin{array}{lll}
\mathrm{M} 7-\mathrm{R} 17: \mathrm{c}-\mathrm{C}_{3} \mathrm{H}_{6} \mathrm{O}+2 \mathrm{~B} s \rightarrow \mathrm{OCH}_{2} \mathrm{CHCH}_{3} s_{2}, & s_{0}=0.75, & E_{A}=95 \mathrm{~kJ} / \mathrm{mol} \\
\mathrm{M} 7-\mathrm{R} 18: \mathrm{OCH}_{2} \mathrm{CHCH}_{3} s_{2} \rightarrow \mathrm{C}_{2} \mathrm{H}_{4}+\mathrm{CH}_{2} \mathrm{O}+2 \mathrm{~B} s, & A=1.0 \times 10^{13} \mathrm{~s}^{-1}, \quad \beta=0, & E_{A}=60 \mathrm{~kJ} / \mathrm{mol}
\end{array}
$$

The ring-opening adsorption of $\mathrm{c}-\mathrm{C}_{3} \mathrm{H}_{6} \mathrm{O}(\mathrm{M} 7-\mathrm{R} 17)$ is modelled as an associative process, requiring two sites, with a near-unity $s_{0}$ of 0.75 and a barrier height estimated from the energetics calculated for the $\mathrm{Cu}^{0} / \mathrm{Cu}^{+}$couple $(95 \mathrm{~kJ} / \mathrm{mol})$. ${ }^{27}$ The $\mathrm{C}-\mathrm{C}$ bond scission and desorption are lumped into a single step 
(M7-R18), with an order-of-magnitude estimate of the pre-exponential, and the barrier height estimated from gas-phase endothermicity of the overall reaction $(\sim 60 \mathrm{~kJ} / \mathrm{mol})$. The results obtained when this mechanism is coupled to the original DTU gas phase chemistry (DTU + M7) are shown in Fig. 8. Sequence M7 significantly reduces the selectivity to $\mathrm{c}-\mathrm{C}_{3} \mathrm{H}_{6} \mathrm{O}(\Delta=-4.27 \%)$ even at the highest bed dilution studied. This is compensated by an increase in $S\left(\mathrm{C}_{2} \mathrm{H}_{4}\right)(\Delta=+2.75 \%), S(\mathrm{CO})(\Delta=+0.83 \%)$, and $S\left(\mathrm{CH}_{2} \mathrm{O}\right)(\Delta=+0.69 \%)$ and suggests that discrepancies in selectivities between the gas-phase model and observed catalytic data may also arise from surface decomposition pathways.

\subsection{Effect of higher flow rates}

With increased inlet flow rates, the experimentally observed conversion drops and the selectivity shifts towards $\mathrm{C}_{3} \mathrm{H}_{6}$. ${ }^{8}$ This blow-off effect is more pronounced under higher dilutions of the catalytic bed, as with $V_{\text {bed }} / V_{\text {cat }}=8.5$ the selectivities to $\mathrm{CO}$ and $\mathrm{CH}_{4}$ obtained at $\sim 40 \mathrm{ml} \mathrm{min}^{-1}$ are almost double of the selectivities at $\sim 160 \mathrm{ml} \mathrm{min}{ }^{-1}$. When the DTU/B mechanism is coupled with the $\mathrm{Os}$-mediated $\mathrm{C}_{3} \mathrm{H}_{6}$ mechanism (M2, - in Fig. 9), the experimental $X\left(\mathrm{C}_{3} \mathrm{H}_{8}\right)(\bullet)$ are well predicted at all studied inlet flow rates and catalyst dilution ratios. Most qualitative trends with increasing flow rates are well captured, including the shape of the blow-off in $S\left(\mathrm{C}_{2} \mathrm{H}_{4}\right), S\left(\mathrm{CH}_{4}\right)$, and $S(\mathrm{CO})$ at $V_{\text {bed }} / V_{\text {cat }} \geq 2.0$. A notable exception is the slightly increasing $S\left(\mathrm{CH}_{4}\right)(\bullet)$ with increased flow rate in the undiluted case. Quantitatively, the agreement of the DTU/B + M2 mechanism with experimental selectivities is poor, as experimental $S\left(\mathrm{C}_{3} \mathrm{H}_{6}\right)(\bullet)$ are overpredicted by the model $(-)$ in all cases, with a maximum absolute deviation $\left(\Delta_{\max }=\max \left(S_{\text {calc }}(\operatorname{prod})-S_{\exp }(\operatorname{prod})\right)\right)$ in $S\left(\mathrm{C}_{3} \mathrm{H}_{6}\right)$ of $+9.6 \%$ (at $V_{\text {bed }} / V_{\text {cat }}=3.5$, $120 \mathrm{ml} \mathrm{min}{ }^{-1}$ ). This leads to a significant underprediction in the $\mathrm{C}-\mathrm{C}$ scission products even with an undiluted catalyst. In section 3.5 we have coupled the DTU/B to the propyl-forming limit pathway (M4) and we have obtained an excellent agreement in the undiluted case at $40 \mathrm{ml} \mathrm{min}^{-1}$ (see …... in Fig. 5). However, as shown in Fig. 9, at higher inlet flow rates, the $S\left(\mathrm{C}_{2} \mathrm{H}_{4}\right)$ is overpredicted $(\cdots \cdots, \Delta=+2.2 \%)$ at the expense of $S\left(\mathrm{C}_{3} \mathrm{H}_{6}\right)(\cdots \cdots, \Delta=-6.3 \%)$. By contrast, in diluted cases with $V_{\text {bed }} / V_{\text {cat }} \geq 2.0$ this combined mechanism struggles to predict the correct $S\left(\mathrm{CH}_{4}\right)(\cdots \cdots)$ and $S\left(\mathrm{C}_{2} \mathrm{H}_{4}\right)$ at low inlet velocities, with $\Delta_{\max }$ in $S\left(\mathrm{C}_{2} \mathrm{H}_{4}\right)=-7.0 \%$. Furthermore, $S(\mathrm{CO})(\cdots .$.$) remains significantly underpredicted. In$ summary, the propylene forming limit mechanism (M2) captures the qualitative trends in selectivities 
with bed dilution and flow rate, and is likely to be a key catalytic pathway. On the other hand, the propyl limit mechanism (M4) produces results that are in better agreement with experiments in undiluted beds, however upon dilution and at higher flow rates it is qualitatively inconsistent with the experimental data. Hence we do not propose it as a credible catalytic pathway.

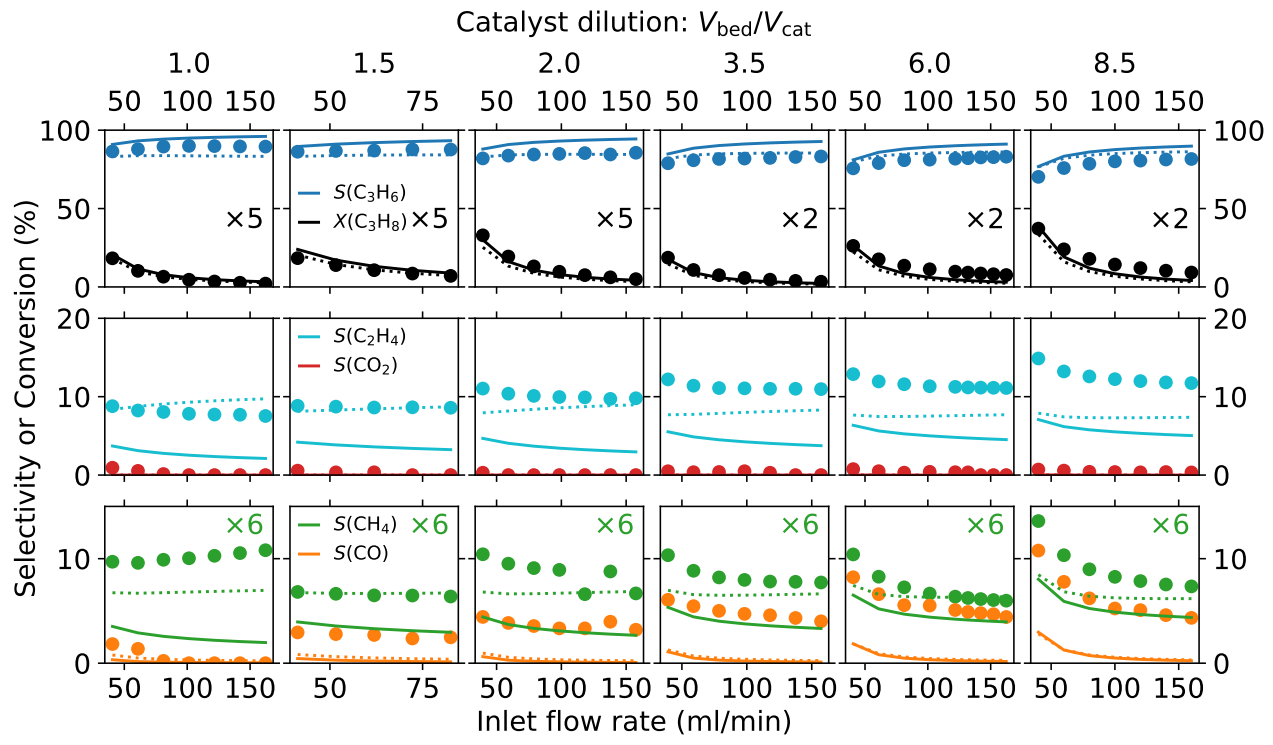

Figure 9: Selectivity and conversion of selected species as a function of inlet flow rate for all studied

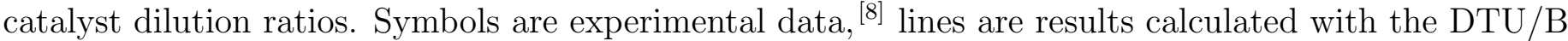
coupled to M2 (.....), and the DTU/B mechanism coupled to a mechanism including $\mathrm{C}-\mathrm{C}$ scission pathways $(-)$. Colour coding as per Fig. 5 .

\subsection{Effect of inlet $\mathrm{O}_{2}$ and $\mathrm{H}_{2} \mathrm{O}$ concentration}

Venegas and coworkers have recently discussed the effects of varying inlet $\mathrm{C}_{3} \mathrm{H}_{8} / \mathrm{O}_{2}$ ratio as well as the impact $\mathrm{H}_{2} \mathrm{O}$ co-feed has on the activity of the catalyst. ${ }^{9}$ Variation in the inlet $\mathrm{C}_{3} \mathrm{H}_{8} / \mathrm{O}_{2}$ ratio has an effect on selectivity, with higher amount of $\mathrm{C}_{2}$ products observed at lower $\mathrm{O}_{2}$ concentrations. On the other hand, co-feeding $\mathrm{H}_{2} \mathrm{O}$ has almost no effect on selectivity, however the activity of the catalyst is increased significantly. The results are supported by density functional theory calculations, identifying a metastable active site that is formed dynamically under operating conditions. The authors propose the catalyst is responsible for activating oxygen, which then readily abstracts hydrogen from propane, yielding $\mathrm{C}_{3} \mathrm{H}_{7}$ radicals. This is at odds with our results above. As also discussed above, the experimental $\mathrm{C}_{2}: \mathrm{C}_{1}$ ratios observed in cases with undiluted beds can be achieved by incorporating surface $\mathrm{C}-\mathrm{C}$ scission pathways. However, the mechanism proposed by Venegas et al. does not include 


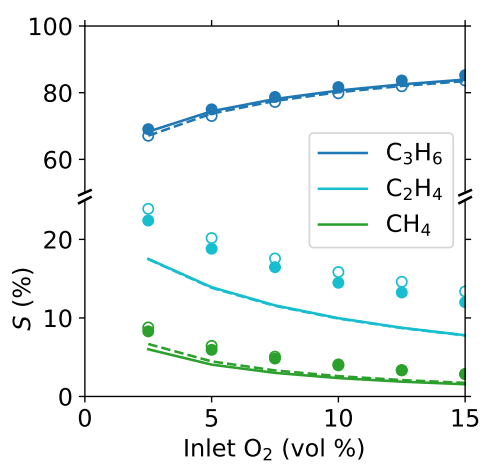

Figure 10: Selectivity to selected species as a function of inlet $\mathrm{O}_{2}$ fraction. Symbols are experimental data, lines are results of calculations with the DTU/B mechanism. Showing cases with inlet $\mathrm{C}_{3} \mathrm{H}_{8}$ fraction of $15 \%(-, \bullet)$ and $25 \%(--, \circ)$, inlet $\mathrm{O}_{2}$ fraction on the abscissa, and $\mathrm{N}_{2}$ as balance.

such pathways. The active sites are regenerated in three ways: i) by recombination of surface hydroxyls followed by desorption of water yielding an empty site, ii) by reaction of surface hydroxyls with gasphase water yielding an activated oxygen site, and iii) by reaction of surface hydrogens with gas-phase $\mathrm{O}_{2}$ yielding peroxy radicals.

In the absence of a validated heterogeneous mechanism, we choose to investigate trends in selectivities caused by the changes in the inlet composition as predicted purely by gas-phase chemistry. We model the system as an adiabatic constant pressure reactor, allowing the inlet mixture to react from a starting temperature of $525^{\circ} \mathrm{C}$, with a pressure of $1 \mathrm{~atm}$, and a final $X\left(\mathrm{C}_{3} \mathrm{H}_{8}\right)$ set to $5 \%$ to allow a close comparison with the experimental data. 9 The results are shown in Fig. 10. The agreement in $S\left(\mathrm{C}_{3} \mathrm{H}_{6}\right)$ and $S\left(\mathrm{CH}_{4}\right)$ is excellent, the most significant discrepancy is the underprediction in $S\left(\mathrm{C}_{2} \mathrm{H}_{4}\right)\left(-, \Delta_{\max }=-6.4 \%\right)$. The underprediction remains roughly constant at all inlet $\mathrm{O}_{2}$ and is comparable to the results shown in Fig. 3. The changes in the behaviour of the gas-phase mixtures upon co-feeding of water are shown in Fig. 11. The results are consistent with the experiments: the ignition behaviour of the water-containing mixture $\left(30 \% \mathrm{C}_{3} \mathrm{H}_{8}, 15 \% \mathrm{O}_{2}, 10 \% \mathrm{H}_{2} \mathrm{O}\right.$, balance $\left.\mathrm{N}_{2}, \cdots \ldots.\right)$ is faster than for the dry inlet composition (- ) by about $20 \%$ at $500^{\circ} \mathrm{C}$, while the selectivity profiles as a function of conversion are unchanged. Therefore, the changes in selectivities upon variation in the $\mathrm{C}_{3} \mathrm{H}_{8} / \mathrm{O}_{2}$ ratio as well as the enhanced activity of the system with steam co-feed can be at least partially attributed to gas-phase phenomena. 

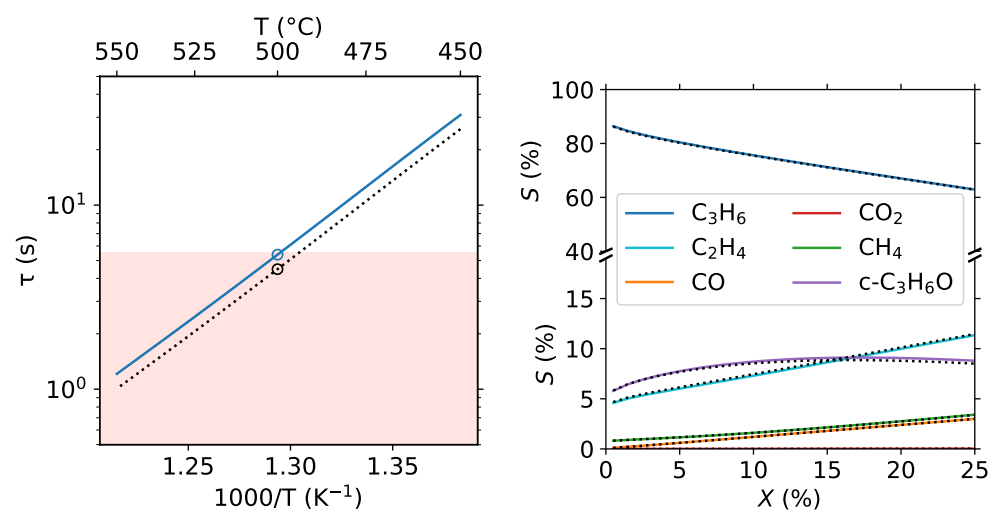

Figure 11: Effect of co-fed $\mathrm{H}_{2} \mathrm{O}$ on gas-phase chemistry. Left: flame ignition delay as a function of initial temperature. Right: Selectivity as a function of conversion. Calculated using the DTU/B mechanism, with dry feed $(-)$ ) and feed containing $10 \% \mathrm{H}_{2} \mathrm{O}(\cdots \cdots)$.

\section{Summary and outlook}

The current work corroborates the hypothesis $[6810]$ that gas-phase chemistry is the main driver of the catalytic performance of $\mathrm{hBN}$ as a selective catalyst for $\mathrm{ODH}$ of propane. The $\mathrm{hBN}$ surface acts as a driver of conversion, however the influence of the surface chemistry on the resulting product distribution decreases significantly with dilution of the catalytic bed, as gas-phase effects begin to dominate. The work highlights the necessity of modelling of the whole heated section of the reactor: even if little to no conversion is observed in blank experiments, and best practices to limit post-catalytic combustion are followed, we show the post-catalytic zone can be responsible for up to $50 \%$ of the total observed conversion.

The propylene limit heterogeneous mechanism featuring the Eley-Rideal mediated propylene forming limit (M2) coupled with the DTU mechanism [11 augmented by propylene oxide pathways from Burluka et al. [13] $(\mathrm{DTU} / \mathrm{B})$ is able to qualitatively predict the experimentally observed propane conversion as well as most trends in selectivities as a function of catalyst dilution and inlet flow rate. A contribution of secondary catalytic pathways is likely necessary to quantitatively reproduce the experimentally observed $\mathrm{C}_{2}: \mathrm{C}_{1}$ product ratio in undiluted beds. However, upon dilution of the catalytic bed all six limit mechanisms converge towards the gas-phase limit, which leads to an underprediction in both $S\left(\mathrm{C}_{2} \mathrm{H}_{4}\right)$ and $S(\mathrm{CO})$ even if those products are formed on the catalyst. The DTU mechanism 11 predicts the formation of a significant amount of propylene oxide, and to a lesser extent acrolein and formaldehyde. The overprediction of propylene oxide is most likely a mechanistic artefact due to missing decomposition 
pathways or catalytic activity of $\mathrm{hBN}$ towards $\mathrm{c}-\mathrm{C}_{3} \mathrm{H}_{6} \mathrm{O}$. The modified DTU/B mechanism is able to predict the observed effects of inlet $\mathrm{C}_{3} \mathrm{H}_{8} / \mathrm{O}_{2}$ ratio on selectivities, and can account for some of the increased activity upon $\mathrm{H}_{2} \mathrm{O}$ co-feed. The $\mathrm{C}_{3}: \mathrm{C}_{2}: \mathrm{C}_{1}$ product distribution predicted using the modified DTU/B mechanism matches the experimentally observed distribution, however the detailed speciation, particularly of $\mathrm{C}_{1}$ oxygenated species, is at odds with the modelled experiments. Further study of the low-temperature oxidation chemistry of the above species is necessary.

Finally, we would like to emphasise the importance of a comprehensive approach to the evaluation of gas-phase kinetics in any mechanistic study involving heterogeneous phenomena at elevated temperatures. One of the key advantages of microkinetics over the Langmuir-Hinshelwood-Hougen-Watson model is the ease with which gas-phase and heterogeneous models of various complexities can be coupled. With open-source solvers, such as Cantera, ${ }^{12}$ the tools are available to everyone; we hope that the executable code archive attached in the Supporting information may encourage wider adoption of such approaches in the catalytic community.

\section{Acknowledgment}

The authors would like to thank Prof. Ive Hermans for valuable comments. PK would like to thank the Forrest Research Foundation for funding.

\section{Supporting information}

Supporting information available. The complete code archive including all calculations, parameter fitting, and plotting scripts is available on Zenodo under DOI: 10.5281/zenodo.4106081. The archive is arranged in a Binder-executable format, see https://mybinder.org/v2/zenodo/10.5281/zenodo. 4106081/?filepath=index.ipynb

\section{References}

[1] J. T. Grant, C. A. Carrero, F. Goeltl, J. Venegas, P. Mueller, S. P. Burt, S. E. Specht, W. P. McDermott, A. Chieregato, and I. Hermans, "Selective oxidative dehydrogenation of propane to propene using boron nitride catalysts," Science, vol. 354, pp. 1570-1573, Dec. 2016. 
[2] L. Shi, D. Wang, W. Song, D. Shao, W.-P. Zhang, and A.-H. Lu, "Edge-hydroxylated boron nitride for oxidative dehydrogenation of propane to propylene," ChemCatChem, vol. 9, pp. 1788-1793, May 2017.

[3] C. A. Carrero, R. Schloegl, I. E. Wachs, and R. Schomaecker, "Critical literature review of the kinetics for the oxidative dehydrogenation of propane over well-defined supported vanadium oxide catalysts," ACS Catal., vol. 4, pp. 3357-3380, Oct. 2014.

[4] P. Chaturbedy, M. Ahamed, and M. Eswaramoorthy, "Oxidative dehydrogenation of propane over a high surface area boron nitride catalyst: Exceptional selectivity for olefins at high conversion," ACS Omega, vol. 3, pp. 369-374, Jan. 2018.

[5] J. T. Grant, W. P. McDermott, J. M. Venegas, S. P. Burt, J. Micka, S. P. Phivilay, C. A. Carrero, and I. Hermans, "Boron and boron-containing catalysts for the oxidative dehydrogenation of propane," ChemCatChem, vol. 9, pp. 3623-3626, Oct. 2017.

[6] J. M. Venegas, W. P. McDermott, and I. Hermans, "Serendipity in Catalysis Research: Boron-Based Materials for Alkane Oxidative Dehydrogenation," Acc. Chem. Res., vol. 51, pp. 2556-2564, Oct. 2018.

[7] L. Shi, D. Wang, and A.-H. Lu, "A viewpoint on catalytic origin of boron nitride in oxidative dehydrogenation of light alkanes," Chinese Journal of Catalysis, vol. 39, pp. 908-913, May 2018.

[8] J. M. Venegas and I. Hermans, "The influence of reactor parameters on the boron nitride-catalyzed oxidative dehydrogenation of propane," Org. Process Res. Dev., vol. 22, pp. 1644-1652, Dec. 2018.

[9] J. M. Venegas, Z. Zhang, T. O. Agbi, W. P. McDermott, A. Alexandrova, and I. Hermans, "Why Boron Nitride is such a Selective Catalyst for the Oxidative Dehydrogenation of Propane," Angew. Chem. Int. Ed., p. 9, 2020.

[10] W. P. McDermott, J. Venegas, and I. Hermans, "Selective oxidative cracking of n-butane to light olefins over hexagonal boron nitride with limited formation of $\mathrm{CO}_{\mathbf{x}}$," ChemSusChem, vol. 13, pp. 152-158, Jan. 2020 .

[11] H. Hashemi, J. M. Christensen, L. B. Harding, S. J. Klippenstein, and P. Glarborg, "High-pressure oxidation of propane," Proceedings of the Combustion Institute, vol. 37, no. 1, pp. 461-468, 2019.

[12] D. G. Goodwin, R. L. Speth, H. K. Moffat, and B. W. Weber, "Cantera: An object-oriented software toolkit for chemical kinetics, thermodynamics, and transport processes." Zenodo, Aug. 2018.

[13] A. Burluka, M. Harker, H. Osman, C. Sheppard, and A. Konnov, "Laminar burning velocities of three $\mathrm{C}_{3} \mathrm{H}_{6} \mathrm{O}$ isomers at atmospheric pressure," Fuel, vol. 89, pp. 2864-2872, Oct. 2010.

[14] H. Wang, E. Dames, B. Sirjean, D. A. Sheen, R. Tango, A. Violi, J. Y. W. Lai, F. N. Egolfopoulos, D. F. Davidson, R. K. Hanson, C. T. Bowman, C. K. Law, W. Tsang, N. P. Cernansky, D. L. Miller, and R. P. Lindstedt, "A high-temperature chemical kinetic model of n-alkane (up to n-dodecane), cyclohexane, and methyl-, ethyl-, n-propyl and n-butyl-cyclohexane oxidation at high temperatures, JetSurF version 2.0," Sept. 2010.

[15] C. F. Goldsmith, W. H. Green, and S. J. Klippenstein, "Role of $\mathrm{O}_{2}+$ QOOH in low-temperature ignition of propane. 1. Temperature and pressure dependent rate coefficients," J. Phys. Chem. A, vol. 116, pp. 33253346, Apr. 2012.

[16] R. Sivaramakrishnan, M.-C. Su, J. V. Michael, S. J. Klippenstein, L. B. Harding, and B. Ruscic, "Shock Tube and Theoretical Studies on the Thermal Decomposition of Propane: Evidence for a Roaming Radical Channel," J. Phys. Chem. A, vol. 115, pp. 3366-3379, Apr. 2011. 
[17] R. Sivaramakrishnan, N. Srinivasan, M.-C. Su, and J. Michael, "High temperature rate constants for OH+ alkanes," Proceedings of the Combustion Institute, vol. 32, no. 1, pp. 107-114, 2009.

[18] H. Wang, X. You, A. V. Joshi, S. G. Davis, A. Laskin, F. N. Egolfopoulos, and C. K. Law, "USC Mech Version II. High-temperature combustion reaction model of $\mathrm{H}_{2} / \mathrm{CO} / \mathrm{C}_{1}-\mathrm{C}_{4}$ compounds.," May 2007.

[19] S. S. Merchant, C. F. Goldsmith, A. G. Vandeputte, M. P. Burke, S. J. Klippenstein, and W. H. Green, "Understanding low-temperature first-stage ignition delay: Propane," Combustion and Flame, vol. 162, pp. 3658-3673, 2015.

[20] O. Deutschmann, R. Schmidt, F. Behrendt, J. Warnatz, and J. Warnat, "Numerical modeling of catalytic ignition," Proc. Combust. Inst., vol. 26, no. 1, pp. 1747-1754, 1996.

[21] P. Kraus and R. P. Lindstedt, "Microkinetic mechanisms for partial oxidation of methane over platinum and rhodium," J. Phys. Chem. C, vol. 121, pp. 9442-9453, May 2017.

[22] V. R. Tarnawski, T. Momose, and W. H. Leong, "Thermal conductivity of standard sands II. Saturated conditions," Int J Thermophys, vol. 32, pp. 984-1005, May 2011.

[23] S. L. Shindé and J. Goela, High thermal conductivity materials. New York: Springer, 2006.

[24] G. Magnani, S. Galvagno, G. Sico, S. Portofino, C. Freda, and E. Burresi, "Sintering and mechanical properties of $\beta$-SiC powder obtained from waste tires," J Adv Ceram, vol. 5, pp. 40-46, Mar. 2016.

[25] J. A. Loiland, Z. Zhao, A. Patel, and P. Hazin, "Boron-containing catalysts for the oxidative dehydrogenation of ethane/propane mixtures," Ind. Eng. Chem. Res., vol. 58, pp. 2170-2180, Feb. 2019.

[26] D. A. Knyazkov, A. M. Dmitriev, O. P. Korobeinichev, K. N. Osipova, G. Pio, A. G. Shmakov, and E. Salzano, "Structure of premixed flames of propylene oxide: Molecular beam mass spectrometric study and numerical simulation," Proceedings of the Combustion Institute, p. S1540748920304296, Sept. 2020.

[27] T.-T. Xiao and G.-C. Wang, "A DFT and microkinetic study of propylene oxide selectivity over copperbased catalysts: effects of copper valence states," Catal. Sci. Technol., vol. 10, no. 22, pp. 7640-7651, 2020.

[28] Z. Kalenik and E. E. Wolf, "The role of gas-phase reactions during methane oxidative coupling," in Methane Conversion by Oxidative Processes: Fundamental and Engineering Aspects, Van Nostrand Reinhold Catalysis Series, p. 548, Springer Science \& Business Media, 2013.

[29] G. Shangpeng, "Crystal structures and band gap characters of h-BN polytypes predicted by the dispersion corrected DFT and GW method," Solid State Communications, vol. 152, pp. 1817-1820, 2012.

[30] M. Hartmann, L. Maier, H. Minh, and O. Deutschmann, "Catalytic partial oxidation of iso-octane over rhodium catalysts: An experimental, modeling, and simulation study," Combustion and Flame, vol. 157, pp. 1771-1782, Sept. 2010.

[31] X. Rozanska, R. Fortrie, and J. Sauer, "Oxidative Dehydrogenation of Propane by Monomeric Vanadium Oxide Sites on Silica Support," J. Phys. Chem. C, vol. 111, pp. 6041-6050, Apr. 2007.

[32] L. Shi, Y. Wang, B. Yan, W. Song, D. Shao, and A.-H. Lu, "Progress in selective oxidative dehydrogenation of light alkanes to olefins promoted by boron nitride catalysts," Chem. Commun., vol. 54, no. 78, pp. 1093610946, 2018.

[33] J. Tian, J. Tan, M. Xu, Z. Zhang, S. Wan, S. Wang, J. Lin, and Y. Wang, "Propane oxidative dehydrogenation over highly selective hexagonal boron nitride catalysts: The role of oxidative coupling of methyl," Sci. Adv., vol. 5, p. eaav8063, Mar. 2019. 
519 [34] A. Lifshitz and C. Tamburu, "Isomerization and decomposition of propylene oxide. Studies with a singlepulse shock tube," J. Phys. Chem., vol. 98, pp. 1161-1170, Jan. 1994. 